\title{
International Evidence on the New Keynesian Phillips Curve Using Aggregate and Disaggregate Data*
}

\author{
Joseph P. Byrne* $\quad$ Alexandros Kontonikas ${ }^{\dagger} \quad$ Alberto Montagnoli ${ }^{\ddagger}$
}

July 09, 2010

\begin{abstract}
We present a unique empirical analysis of the properties of the New Keynesian Phillips Curve using an international dataset of aggregate and disaggregate sectoral inflation. Our results from panel time-series estimation clearly indicate that sectoral heterogeneity has important consequences for aggregate inflation behaviour. Heterogeneity helps to explain the overestimation of inflation persistence and underestimation of the role of marginal costs in empirical investigations of the NKPC that use aggregate data. We find that combining disaggregate information with heterogeneous-consistent estimation techniques helps to reconcile, to a large extent, the NKPC with the data.
\end{abstract}

Keywords: New Keynesian Phillips Curve; Heterogeneity; Aggregation Bias.

JEL classification: E31, E52.

${ }^{*}$ We would like to thank Mario Cerrato, Jean Imbs, Bob Hart, Campbell Leith, Jim Malley, David Mayes, Ron Smith, Boriss Siliverstovs, Jan-Egbert Sturm and the participants at the KOF Research Seminar for their most useful comments and suggestions. Any remaining errors are sole responsibility of the authors.

*Department of Economics, University of Glasgow, Glasgow, G12 8RT, UK, j.byrne@lbss.gla.ac.uk

${ }^{\dagger}$ Department of Economics, University of Glasgow, Glasgow, G12 8RT, UK, a.kontonikas@lbss.gla.ac.uk

${ }^{\ddagger}$ Division of Economics, University of Stirling, Stirling, FK9 4LA, UK, alberto.montagnoli@stir.ac.uk 


\section{Introduction}

A cornerstone of modern macroeconomics is the assertion that changes in a firm's prices are driven by real marginal costs (see e.g. Gali and Gertler (1999), Woodford (2003) and Walsh (2010)). The New Keynesian Phillips Curve (NKPC) is derived from a micro-founded model, in which forward-looking firms in monopolistically competitive industries optimally set their prices as a mark-up over their marginal costs. This essentially microeconomic theory has important policy implications at the aggregate level based upon a representative agent model. In fact in a framework with no inflation inertia, monetary policy can reduce costlessly the level of inflation and a credible commitment can ensure output is close to its potential level. Moreover, if the NKPC is correct, the notion of NAIRU is meaningless in driving efficient economic policies. ${ }^{1}$

Despite the prominence of the New Keynesian Phillips Curve in theoretical work, there are a number of unresolved empirical issues. Firstly, the extent to which current inflation is driven by its future expectations and its past values. Secondly, the role of marginal costs in driving the dynamics of prices; in this regard, some authors have recently cast doubts on the ability of the marginal costs, measured as the labour share of income, to explain inflation dynamic (see for instance Rudd and Whelan (2005) and Lawless and Whelan (2007)). Thirdly, the degree of heterogeneity across sectors. Finally, there is an open debate on the appropriate estimation method. We are of the view that these issues are intrinsically related to one another.

The NKPC has typically been estimated by Generalised Method of Moments (GMM). Here the forward-looking component in an inflation equation is replaced by realized values and instruments are used. This method has come under scrutiny and criticism; its sensitivity to the choice of instruments and its poor small sample properties are just some of the problems that have been associated with the GMM. (see e.g. Rudd and Whelan (2005), Kurmann (2007), Stock et al. (2002) and Dufour et al. (2006)). In addition, and germane to the current study, GMM estimators are problematic with panels of disaggregate data. Arellano and Bond (1991) Dynamic Panel GMM may not be felicitous for a sectoral NKPC study with heterogeneous responses and disaggregate instruments may be more challenging to obtain, for example with surveys of disaggregate expectations. ${ }^{2}$

The literature has proposed some alternatives to the GMM estimator. Fuhrer et al. (1995) and Linde (2005) show that a full-information approach has some advantages over GMM. Assum-

\footnotetext{
${ }^{1}$ See Rudd and Whelan (2005) for a discussion on this point.

${ }^{2}$ However see Dees et al. (2009) for an approach which uses global factors as possible instruments.
} 
ing a particular data generating process for marginal costs allows one to use Maximum Likelihood (ML) for estimation (see e.g. Sbordone (2002); Kurmann (2007)). Finally, the closed-form solution approach has been proposed by Rudd and Whelan (2005, 2006, 2007), whereas inflation is expressed as a function of its own past value and a composite forward-looking term of expected future marginal costs.

The NKPC has been extensively estimated using aggregate macroeconomic data. Work using aggregate NKPC include papers by Gali and Gertler (1999), Sbordone (2002), Rudd and Whelan (2005) and Dees et al. (2009). This is subject to various assumptions, without a doubt the most important is that all firms and sectors show the same degree of price stickiness. There has been some evidence against this conjecture using time series methods (see Clark (2006) and Altissimo et al. (2006)) and also theory-consistent estimated models (see Leith and Malley (2007) for US evidence and Imbs et al. (2009), henceforth IJP, for French evidence). If there is heterogeneity in the data and the dynamic panel model inappropriately imposes homogeneity, aggregation bias will increase inflation persistence and also reduce the significance of the exogenous determinants where these are highly persitent (see Pesaran and Smith (1995) and Pesaran et al. (1996)). This may be of considerable importance in the New Keynesian empirical literature that has found it difficult to identify a consistent role for real marginal costs and has emphasized substantial inflation inertia. ${ }^{3}$

In contrast to the large number of studies that utilized aggregate data and time-series estimation techniques to assess the relationship between inflation and marginal costs, only a few studies applied panel estimation methods on disaggregate data. We find the paucity of disaggregate NKPC studies rather puzzling, given that, as Lawless and Whelan (2007) explain, we would expect the NKPC model to be more successful when applied to sectoral data. IJP employ the Mean Group (MG) estimator in order to obtain the characteristics of the representative French sector and compare them to those implied by the aggregated data. Their findings for the representative sector indicate that the estimated persistence of inflation is smaller and the real marginal cost coefficient larger, as compared to the aggregate level, thereby confirming the empirical importance of sector-level heterogeneity and its effects on the aggregate. Jondeau and Pelgrin (2009) develop a heterogeneity-correcting estimation technique and apply it to French sectoral data to assess the hybrid NKPC. They find that these unbiased estimates are very close to those obtained using the MG heterogeneous panel estimator. Lawless and Whelan (2007)

\footnotetext{
${ }^{3}$ The fact that the use of aggregate data might not be the most reliable is supported by empirical evidence showing that firms' and economic sectors' behavior is not homogeneous, see e.g. Bils and Klenow (2004), Dhyne et al. (2005), Byrne et al. (2010).
} 
employ the MG estimator to assess the pure forward-looking NKPC model with international sectoral data. Their results do not support the fully forward-looking specification as a model of the inflation process since the average estimated real marginal cost coefficient is negative. Leith and Malley (2007) also present evidence of important sectoral differences using US data.

In light of the points discussed above, we seek to contribute to the empirical literature on NKPC in a number of directions. Our approach starts from the theoretical model of IJP, where the heterogeneity of pricing behavior is shown to be of great importance for the appropriate NKPC estimation approach. We estimate the NKPC using data from the EU KLEMS database covering 15 economic sectors and 14 OECD countries. This database provides harmonized data on prices, output and labour compensation and, to the best of our knowledge, has not been utilized before in this literature. We utilise both time-series and panel estimation approaches. Our baseline time-series estimation technique is Full Information Maximum Likelihood (FIML), rather than GMM. Furthermore, we use the Common Correlated Effect (CCE) technique of Pesaran (2006) in order to adjust for the possibility that shocks to inflation or marginal costs may be cross-sectionally correlated. Finally, in our panel estimations we employ not only the standard MG estimator, which assigns equal weights to the individual units, but also the Weighted Mean Group (WMG) estimator, which utilises observed national and sectoral weights, in order to account for the fact not all countries and sectors are equally economically important.

Previewing our results, we find little evidence of marginal costs's importance in the aggregate country time-series estimations. Moreover, our results indicate considerable sectoral heterogeneity. Once we account for this feature, by applying the heterogeneous panel MG and WMG estimators on disaggregate data, we find stronger evidence for the role of marginal costs as determinants of inflation, while the estimated inflation persistence declines. Our results indicate that the use of disaggregate data leads to greater support for the NKPC model of inflation in general and the notion of dominant forward-looking behavior in particular. In terms of our alternative estimation techniques, we find that the empirical adjustment for cross-sectional correlation leads to lower inflation persistence. Furthermore, the significance of marginal costs is affected by the weighting scheme, with a more prominent role for them indicated when using observed weights. Nevertheless, there are important difference across the countries. For the US, Germany, the UK and France, the NKPC provides a good approximation of the data, with relatively low inflation persistence and a statistically significant marginal cost effect. On the other hand, the NKPC does not work so well in some of the smaller countries in our dataset. 
The remainder of the paper is structured as follows. Section 2 describes the theoretical background. In section 3 we present the econometric framework. Section 4 discusses the data. Section 5 presents the empirical results. Section 6 concludes.

\section{The New Keynesian Phillips Curve}

In this section we summarize the IJP sectoral hybrid New Keynesian Phillips Curve which builds upon previous work by Sbordone (2002), Woodford (2003), and Gali and Gertler (1999). First we set out demand for firm $i$ output, $Y_{i j, t}$, in monopolistically competitive sector $j$ :

$$
Y_{i j, t}=\left(\frac{P_{i j, t}}{P_{j, t}}\right)^{-\eta} Y_{j, t}
$$

where $P_{i j, t} / P_{j, t}$ is the relative price of firm $i$ 's production of good $j, \eta>1$ is the elasticity of substitution across varieties and $Y_{j, t}$ is sectoral output. The production function specifies that output is produced by each firm using labour, $H_{i j, t}$ :

$$
Y_{i j, t}=Z_{j, t} H_{i j, t}^{1-a_{j}}
$$

where $Z_{j, t}$ is sector specific labour productivity and $1-a_{j}$ is the share of labour in $j$ sector's value added.

In line with Gali and Gertler (1999), two types of firms co-exist. A proportion of firms behave in a forward-looking manner, as in Calvo (1983)'s model, by setting prices with the aim of maximizing the expected stream of real profits, while the remaining firms follow a backwardlooking rule of thumb which is based on the recent history of aggregate prices. Furthermore, the probability that firms in sector $j$ are not able to re-optimize their prices is fixed. The hybrid version of the NKPC can then be derived for sector $j$ :

$$
\pi_{j, t}=\lambda_{j}^{b} \pi_{j, t-1}+\lambda_{j}^{f} E_{t} \pi_{j, t+1}+\theta_{j} s_{j, t}+\varepsilon_{j, t} \quad ; \quad 0<\lambda_{j}^{b} \gtreqless \lambda_{j}^{f}>0, \theta_{j}>0
$$

This reduced form equation suggests that current period inflation, $\pi_{j, t}$, is a function of lagged

and expected inflation, where $\lambda_{j}^{b}$ and $\lambda_{j}^{f}$ functions of the underlying 'deep parameters': the degree of backward-lookingness in price setting, the degree of price stickiness, and the discount factor. Also current period inflation is a function of real marginal costs, $s_{j, t}$, with parameter $\theta_{j}$. The error term $\varepsilon_{j, t}$ is a cost-push shock, $\sigma_{\varepsilon j}^{2}=E\left(\varepsilon_{j, t}^{2}\right)$. We account for cross sectional correlation in 
error terms in our subsequent empirical estimation.

\section{Econometric Framework}

The vast majority of previous empirical studies have utilized aggregate data and time-series methodologies in order to estimate the hybrid NKPC. In order to deal with the forward-looking inflation term, many studies on aggregate inflation dynamics have employed instrumental variables estimation techniques such as the generalized method of moments (GMM), see e.g. Gali and Gertler (1999) and Gali et al. (2001). Essentially, expected future inflation is replaced by its realized value and instruments are utilized which are assumed to be correlated with expected inflation and orthogonal to the residuals. As Kurmann (2007) points out, these estimators make few assumptions about expectations and implementation is relatively costless. Nevertheless, various problems have been identified in the GMM approach such as relative inefficiency, sensitivity to the choice of instruments, poor small sample properties when instruments are weakly identified and normalization issues (see e.g. Stock et al. (2002) and Dufour et al. (2006)). Furthermore, GMM estimators are particularly problematic with panels of disaggregate data. Specifically, instrumentation affects the properties of heterogeneous panel estimators and a set of instruments which are correlated with expected sectoral inflation, but orthogonal to the residuals, is typically not available. ${ }^{4}$ Fuhrer et al. (1995) and Linde (2005) show that a full-information approach, whereas Eq. (3) is estimated conditional upon a fully structural general equilibrium model, has some advantages over the GMM such as more efficiency and improvement of the small sample properties of the estimates. The drawback of this method, though, is conditionality upon correct specification of the general equilibrium model of the economy.

A third approach that has been employed in the literature assumes a data generating process for marginal costs and uses Maximum Likelihood (ML) for estimation (see e.g. Sbordone (2002); Kurmann (2007)). IJP adopt this method and solve the forward-looking term out of Eq. (3) under the assumption that (quarterly) marginal costs follow a second order autoregressive process, $\mathrm{AR}(2)$. This approach is related to the closed-form solution approach that Rudd and Whelan (2005, 2006, 2007) propose. Particularly, Rudd and Whelan obtain the closed-form solution of the hybrid NKPC, which expresses inflation as a function of its own past value and a composite forward-looking term of expected future marginal costs, and subsequently estimate it. The key difference between the two studies is the additional assumption of backward-looking marginal costs by the former, which allows for the derivation of an analytical expression relating inflation

\footnotetext{
${ }^{4}$ See Imbs et al. (2007) for a detailed discussion of the instrumentation problem.
} 
to its own past value and the current (and lagged, due to $\mathrm{AR}(2)$ assumption) value of the real marginal cost. Hence, there is no need to either construct an empirical proxy for the infinite discounted sum of the expected future marginal costs or to employ GMM-based techniques in order to directly estimate the closed form-solution.

We employ a similar approach, in that the real marginal cost is backward-looking, with the difference that we assume a first order autoregressive process, $\operatorname{AR}(1):^{5}$

$$
s_{j, t}=\rho_{j} s_{j, t-1}+u_{j, t}
$$

where $\left|\rho_{j}\right|<1, u_{j, t}$ is an identically and independently distributed shock to real marginal costs in sector $j, \sigma_{u j}^{2}=E\left(u_{j, t}^{2}\right)$.

Furthermore, we assume that $\lambda_{j}^{f}+\lambda_{j}^{b}=1$, which precludes the existence of a long-run level trade-off between inflation and real marginal costs. This assumption provides the necessary identifying restriction, given the $\operatorname{AR}(1)$ specification for marginal costs, and is consistent with many previous studies of the New Keynesian framework (see e.g. Christiano et al. (2005); Jondeau and Le Bihan (2008); Rudd and Whelan (2006)). The closed-form solution to the hybrid NKPC under AR(1) marginal costs is given by: ${ }^{6}$

$$
\pi_{j, t}=\delta_{j} \pi_{j, t-1}+\xi_{j} s_{j, t}+v_{j, t}
$$

where $\delta_{j}=\lambda_{j}^{b} /\left(1-\lambda_{j}^{b}\right), \xi_{j}=\theta_{j} /\left(1-\lambda_{j}^{b}\right)\left(1-\rho_{j}\right)$ and $v_{j, t}=\varepsilon_{j, t} /\left(1-\lambda_{j}^{b}\right)$.

Our baseline empirical strategy proceeds as follows. First, we estimate the system formed by Eqs. (4) and (5) with FIML for every sector and country in our dataset. Having obtained the estimates of $\delta_{j}, \xi_{j}$ and $\rho_{j}$ we then recover the hybrid NKPC parameters as follows: ${ }^{7}$

$$
\begin{gathered}
\lambda_{j}^{b}=\delta_{j} /\left(1+\delta_{j}\right) \\
\lambda_{j}^{f}=1 /\left(1+\delta_{j}\right) \\
\theta_{j}=\xi_{j}\left(1-\rho_{j}\right)\left(1-\lambda_{j}^{b}\right)
\end{gathered}
$$

\footnotetext{
${ }^{5}$ This assumption is reasonable given the annual frequency of our dataset and is validated by our empirical results.

${ }^{6}$ See Appendix A for more details.

${ }^{7}$ Note that the estimates of $\lambda^{b}, \lambda^{f}$ and $\theta$ that we obtain with this (indirect) approach are numerically identical to those obtained from estimating directly the system formed by Eq. (4) and Eq. (A4) in Appendix A.
} 
Second, we average the individual time-series coefficients' estimates to obtain the MG panel estimator, $\widehat{\Psi}_{M G}$, (see Pesaran and Smith (1995)):

$$
\widehat{\Psi}_{M G}=\frac{1}{N} \sum_{j=1}^{N} \widehat{\Psi}_{j}
$$

where $\widehat{\Psi}_{j}$ denotes the individual estimates. The standard error of the MG estimator is:

$$
s e\left(\widehat{\Psi}_{M G}\right)=\sqrt{\frac{1}{N(N-1)} \sum_{j=1}^{N}\left(\widehat{\Psi}_{j}-\widehat{\Psi}_{M G}\right)^{2}}
$$

The MG estimator accounts for sectoral (and national) heterogeneity. Hsiao et al. (1999) present evidence that the mean group estimator is consistent and distributed normally asymptotically for reasonable N and T. Previous evidence by IJP for France and Leith and Malley (2007) for the US supports the notion of heterogeneous sectoral Phillips curves. In the process of calculating the MG estimates the individual time-series results are averaged using four alternative groupings: (i) we average results across all countries using aggregate data, and (ii) disaggregate data; (iii) we calculate country-specific averages using the sectors as cross-sectional units (e.g. German agriculture, hunting and forestry, German construction, etc); (iv) we calculate sectorspecific averages using the countries as cross-sectional units (e.g. French construction, German construction, etc). This will allow us to examine the patterns of the inflation-real marginal cost relationship both within and across countries and sectors.

\subsection{Weighted Mean Group Estimator}

The standard MG estimator assigns equal weights $(=1 / N)$ to the individual estimates, see Pesaran and Smith (1995). Hence it may misrepresent aggregate estimates since not all sectors are equally important. Similarly, not all countries are equally important in terms of their contribution to total global output, which is relevant when considering international experience. To construct a more representative estimate, in addition to the MG estimator, we use the WMG estimator, $\widehat{\Psi}_{W M G}$, which takes into account Gross Value Added (GVA) based weights $\left(=w_{j}\right)$ of each sector and country: ${ }^{8}$

\footnotetext{
${ }^{8}$ The consistency of the estimator is not affected by the weighting scheme. The Random Coefficients (RC) estimator of Swamy (1970), which uses weights that are inversely proportional to the covariance matrices of the least squares estimates, and the MG estimator are asymptotically equivalent (see Hsiao and Pesaran (2008). Imbs et al. (2007) report very similar results from panel estimates that use the aforementioned RC weights as well as observed weights (sectoral shares in the GDP deflator) similar to the ones that we employ.
} 


$$
\begin{gathered}
\widehat{\Psi}_{W M G}=\sum_{j=1}^{N} w_{j} \widehat{\Psi}_{j} \\
\operatorname{se}\left(\widehat{\Psi}_{W M G}\right)=\sqrt{\frac{w_{j}}{N-1} \sum_{j=1}^{N}\left(\widehat{\Psi}_{j}-\widehat{\Psi}_{W M G}\right)^{2}}
\end{gathered}
$$

In order to calculate the national weights that are required for grouping (i) we divide the average national GVA by the sum of the average national GVAs across the sample countries. Grouping (ii) calls for weights that reflect the importance of each sector in each country for total international output. To obtain these we divide the average sectoral GVA of the given country by the sum of the average national GVAs across the sample countries. For grouping (iii) we calculate sectoral weights within a given country by dividing the average sectoral GVA by the average national GVA. Finally, the relative importance of a given country for a given sector that is needed for grouping (iv) is measured by the ratio of the average sectoral GVA of the given country to the sum of the average sectoral GVAs across the sample countries. ${ }^{9}$

\subsection{Adjusting for cross-sectional correlation}

The FIML time-series estimation approach does not account for the possibility that shocks to inflation or the real marginal cost may be cross-sectionally correlated. We use the CCE technique of Pesaran (2006) to account for potential unobserved common factors reflecting cross-sectional linkages or common macroeconomic shocks. Hence, Eqs. (4) and (5) are augmented by an auxiliary explanatory variable, the cross-sectional average of the regression's variables, which filters common linkages out. ${ }^{10}$ The resulting system of equations is:

$$
\begin{gathered}
\pi_{j, t}=\delta_{j} \pi_{j, t-1}+\xi_{j} s_{j, t}+f_{j, t}^{\pi^{\prime}} \gamma_{\pi, j}+\bar{v}_{j, t} \\
s_{j, t}=\rho_{j} s_{j, t-1}+f_{j, t}^{s^{\prime}} \gamma_{s, j}+\bar{u}_{j, t}
\end{gathered}
$$

where $f_{j, t}^{\pi}=\left(\bar{\pi}_{t}, \bar{\pi}_{t-1}, \bar{s}_{t}\right)^{\prime}, f_{j, t}^{s}=\left(\bar{s}_{t}, \bar{s}_{t-1}\right)^{\prime}, \bar{x}_{t}$ is the cross-sectional average of $x_{j, t}$ and $\bar{u}_{j, t}$ $\left(\bar{v}_{j, t}\right)$ denotes an independently and identically distributed shock to real marginal costs (inflation) in sector $j$. We now proceed to a detailed discussion of the data set and then the results.

\footnotetext{
${ }^{9}$ The GVAs that we use for the calculation of weights for groupings (i), (ii) and (iv) are expressed in common terms using 1997 German currency PPPs. The latter are provided by EU KLEMS.

${ }^{10} \mathrm{IJP}$ also use this approach and point out that it is not the same as constructing an explicit model of sectoral technological linkages. For relevant theoretical contributions see among others Carvalho (2006) and Sheedy (2007).
} 


\section{Data}

Our data is sourced from the EU KLEMS database (http://www.euklems.net). This contains harmonized data for a range of countries on economic growth, prices, labor participation and labor compensation at both aggregate and sectoral level, see van Ark et al. (2008) for a discussion. In our analysis, we use data for 14 industrial countries: Austria, Belgium, Denmark, France, Germany, Greece, Ireland, Italy, Netherlands, Portugal, Spain, Sweden, UK and USA. Sectoral data covers 15 economic sectors including agriculture, manufacturing and services: agriculture, hunting and forestry; fishing; mining and quarrying; total manufacturing; electricity, gas and water supply; construction; wholesale and retail trade; hotels and restaurants; transportation, storage and communication; financial intermediation; real estate, renting and business activities; public administration, defence and compulsory social security; education; health and social work; other community, social and personal services. Thus, the EU KLEMS database makes it possible to analyze the performance of the hybrid NKPC at both national and sectoral level.

The EU KLEMS database has annual frequency over the period 1971-2005 (i.e. $T=35) .{ }^{11}$ In the tradeoff between comprehensiveness and harmonization, on the one hand, and reduced frequency, on the other, we believe that the benefits of the former outweigh the potential costs of the latter. The main drawback from annual frequency would materialize if one used this dataset to try to uncover the structural parameters that underlie the hybrid NKPC. Particularly, with annual data, the the minimum implied duration of price rigidities, which is equal to one (for zero price stickiness), corresponds to one year. This lower bound is too high given the findings in a number of studies which use disaggregated data and suggest durations of less than one year (see e.g. Bils and Klenow (2004); Nakamura and Steinsson (2008)). Hence, structural estimation using annual disaggregated data is not recommended since it would, most likely, overestimate duration.

We measure $\pi_{j, t}$ as the demeaned growth rate of the value added deflator in sector $j$, while $s_{j, t}$ is proxied by the log-deviation of the labor share of income in value added from its sample mean in sector $j$ (see also Gali and Gertler (1999)). The labor share of income is measured as labour compensation per employee times total number of employees divided by the GVA.

Our calculation of GVA based weights reveals that at sectoral level, three sectors dominate

\footnotetext{
${ }^{11}$ Estimations of the the hybrid NKPC using annual data have also been carried out by Lawless and Whelan (2007), and Rudd and Whelan (2006). Rudd and Whelan (2006) argue that the use of annual data helps to investigate the possibility that the results from the frequently employed quarterly datasets are affected by the 'noise' inherent in higher frequency data (measurement errors or other transitory shocks in inflation). They find that their main conclusion, i.e. that the hybrid NKPC fails to provide a useful empirical description of the inflation process, does not depend on the use of quarterly data.
} 
by contributing, on average, almost $50 \%$ of GVA in every sample country: total manufacturing and two service sectors, that is, wholesale and retail trade, and real estate, renting and business activities (see Table B1 in Appendix B). At the international level, the US contributes on average around $50 \%$ of the total GVA across the sample countries (see Table B2-Panel B in Appendix B). The dominant role of the US is made more explicit if we consider its contribution to the GVA of each sector. Our results typically indicate, where the US contributes on average 15\%, in every other sector it leads with its share ranging from $44 \%$ in health and social work to $67 \%$ in mining and quarrying (see Table B2-Panel A in Appendix B).

\section{Results}

We first present and discuss the aggregate data time-series estimation results based upon FIML. These are helpful as a benchmark and seem consistent with previous aggregate results. We then proceed to the disaggregate panel estimation results, accounting more fully for sectoral heterogeneity.

\subsection{Time-Series Estimates}

Table 1 reports the aggregate data FIML time-series estimation results for the hybrid NKPC. ${ }^{12}$ Estimates of the autoregressive coefficient on the real marginal cost $(\rho)$ are always statistically significant and range substantially. Across the sample countries, the average $R^{2}$ in the autoregressive models of aggregate marginal costs is around 0.8, indicating an overall good fit. ${ }^{13}$ Thus, we are confident that the $\mathrm{AR}(1)$ model provides a good representation of the real marginal cost's dynamics in our dataset. ${ }^{14}$

[TABLE 1 HERE]

Estimates of the coefficient of past inflation in the closed form solution to the hybrid NKPC $(\delta)$ are almost all significantly different from zero. In every country in our dataset, the estimate of the coefficient on past inflation $\left(\lambda^{b}\right)$ lies below the coefficient on expected future inflation $\left(\lambda^{f}\right)$. The degree of inflation's backward-looking behavior ranges from virtually zero in Austria

\footnotetext{
${ }^{12}$ The FIML time-series estimates of $\delta, \xi$ and $\rho$ in Table 1 are obtained from estimating the system formed by Eqs. (4) and (5) using aggregate data.

${ }^{13}$ Results are available upon request.

${ }^{14}$ The AR(1) model still exhibits good fit when we employ disaggregate real marginal cost data, with the average $R^{2}$ (across all countries and sectors) being equal to 0.73 .
} 
to 0.464 in Portugal. Compared to the other sample countries, Germany exhibits lower inflation persistence. This finding is in agreement with previous GMM evidence for five Euro Area countries by Benigno and Lopez-Salido (2006), who nevertheless report significantly lower estimates of $\lambda^{b}$ for Germany. The estimated importance of back-ward looking inflation for the US (i.e. $\lambda^{f}$ $=0.587)$ is in line with Gali et al. (2001) GMM estimates of the hybrid model.

Crucially, the FIML results in Table 1 do not support the existence of a strong empirical relationship between inflation and marginal costs at the aggregate level. Estimates of the slope coefficient on the real marginal cost in the closed-form solution $(\xi)$ are significantly different from zero at the $5 \%$ level only in 3 of the 14 countries (i.e. Austria, France and Greece), while estimates of the corresponding coefficient, $\theta$, in the hybrid NKPC are statistically insignificant in all countries. ${ }^{15}$ Hence, our aggregate time-series results indicate that marginal costs do not significantly affect inflation in agreement with a number of recent time-series studies including, among others, Bardsen et al. (2004), Nason and Smith (2008), and Rudd and Whelan (2006, 2007). Related to this point, Rudd and Whelan (2007) argue that focusing only on the point estimates of $\lambda^{b}$ and $\lambda^{f}$ can lead to inappropriate conclusions about the importance of rational forward-looking expectations in price setting and the overall success of the NKPC. Particularly, they point out that the commonly employed interpretation of the finding $\lambda^{b}<\lambda^{f}$ as supportive of the view that forward-looking behavior is dominant is not appropriate if, at the same time, the effect of marginal costs on inflation is statistically insignificant. ${ }^{16}$ Finally, similar patterns in aggregate data time-series results, in terms of $\lambda^{b}<\lambda^{f}$ and insignificant real marginal cost coefficient, are obtained when we adjust for cross-sectional correlation using the CCE methodology. ${ }^{17}$

The disaggregate data time-series estimation results are available upon request but not shown in the paper to conserve space. In summary, the results suggest that inflation dynamics matter, with $\delta$ estimates being statistically significant in, at least, half of the sectors in most countries with FIML. Furthermore, in most countries there is at least one sector where $\xi$ is positive and significantly different from zero indicating some empirical support for the theoretical role of marginal costs for inflation at the sectoral level. Nevertheless, at the same time there are also some instances of negative and significant sectoral $\xi$ 's which are not compatible with the

\footnotetext{
${ }^{15}$ In order to conduct hypothesis tests for $\lambda^{b}, \lambda^{f}$ and $\theta$ in a time-series context, we estimate these coefficients directly (by FIML) using the system formed by Eq. (4) and Eq. (A4) in Appendix A. See also the discussion in Foonote 6 regarding the numerical equivalence of the direct and indirect time-series estimation approaches.

${ }^{16}$ In agreement with our aggregate data time-series results in Table 1 and Table B3 in Appendix B, Rudd and Whelan (2007) obtain estimates of the closed-form solution of the hybrid NKPC which imply that $\lambda^{b}<\lambda^{f}$, while at the same time the impact of marginal costs on inflation is statistically insignificant.

${ }^{17}$ See Table B3 in Appendix B. The CCE time-series estimates of $\delta, \xi$ and $\rho$ in that table are obtained from estimating the system formed by Eqs. (13) and (14).
} 
New Keynesian pricing theory. ${ }^{18}$ Finally, the results indicate considerable sectoral heterogeneity which will be accounted for in the following section via the heterogeneous MG panel estimator. In order to visualize the sectoral heterogeneity, Figures 1-3 show the sectoral estimates of $\delta, \xi$ and $\rho$ in France, Germany, Italy, UK and the US, which together account for almost $90 \%$ of the total GVA, on average, across the sample countries.

[FIGURES 1-3 HERE]

\subsection{Panel Estimates}

The MG and WMG panel estimates of the hybrid NKPC in Table 2 average the FIML and CCE time-series estimation results using aggregate and disaggregate data for all the sample countries. ${ }^{19}$ The panel estimates of $\rho$ are statistically significant in every case. In the case of aggregate data estimations, allowing for GVA based weights and/or cross-sectional correlation leads to lower estimates of real marginal cost persistence. On the other hand, the disaggregate data estimates of $\rho$ do not vary significantly across the different estimation methods. They range from 0.795 to 0.863 indicating significant inertia in the real marginal cost.

\section{[TABLE 2 HERE]}

Table 2 reveals some very interesting patterns regarding inflation dynamics. First, the panel estimate of the coefficient on expected future inflation is greater than that of past inflation across all estimation methods. Second, as we switch from aggregate to disaggregate data, inflation persistence declines. For example comparing the aggregate and disaggregate data MG-FIML results, we can see that the estimate of $\lambda^{b}$ declines from 0.389 to 0.272 . The finding that adjustment at the disaggregate level is much more rapid than at the aggregate level, leading to lower estimates of inflation persistence is in line with previous evidence based upon autoregressive time-series models (see e.g. Altissimo et al. (2006, 2007); Byrne et al. (2010)), as well as French panel data evidence by IJP. Third, adjusting for cross-sectional correlation using the CCE methodology leads to higher estimates of the forward-looking component of inflation dynamics. For example, using aggregate data and MG (WMG) $\lambda^{f}$ increases from 0.611 to 0.783 (0.602 to

\footnotetext{
${ }^{18}$ For example, using FIML, we obtain negative and significant time-series estimates of $\xi$ in two UK sectors: construction and education.

${ }^{19}$ For example, equal weights and GVA based weights averages of the aggregate data FIML time-series estimates in Table 1 generate the aggregate data MG-FIML and WMG-FIML panel estimates of the hybrid NKPC shown in the second and fourth column of Table 2, respectively.
} 
0.824) when we use CCE instead of FIML. Fourth, adjusting for GVA based weights does not seem to considerably affect inflation dynamics. ${ }^{20}$

While inflation dynamics are largely unaffected by the weighting method, there are important implications for the statistical significance of the real marginal cost in the aggregate data estimations. Particularly, aggregate data panel estimates of $\xi$ and $\theta$ are significantly different from zero when WMG is used instead of MG. This finding reflects the facts that the US timeseries estimates of these parameters in Table 1, which are used as input for the panel estimator, are quite large in magnitude and that the US receives the largest weight in WMG. The disaggregate data panel estimates of the aforementioned coefficients are statistically significant in all cases apart from MG-CCE. Using disaggregate data, the WMG-CCE panel estimates yield very strong support for forward-looking behaviour since, not only the marginal costs' effect on inflation is positive and statistically significant, but also $\lambda^{f}$ is close to one (0.913).

[TABLE 3 HERE]

The country-specific MG-FIML panel estimates of the hybrid NKPC in Table 3 report the characteristics of the average (or representative) sector in each of the sample countries. Comparing these results, which are based upon disaggregate data, with those in Table 1, which perform FIML estimation on aggregate data, we obtain important insights on the empirical relevance of heterogeneity at a country-by-country basis. First, with the exception of Austria, the estimates of the extent of inflation's backward-looking behavior are lower across the sample countries when we use the heterogeneous MG-FIML panel estimator that takes into account sectoral information. For example, the US estimate of $\lambda^{b}$ in Table 3 is 0.195 , that is, less than half of its aggregate data homogenous counterpart in Table $1(0.413) .{ }^{21}$ Second, in contrast to the aggregate data time series results, disaggregate data panel estimates indicate a more prominent role for marginal costs. Estimates of $\theta$ in Table 3 are positive and significantly different from zero in five cases, as opposed to none in Table 1. Thus, once we allow for sectoral heterogeneity, marginal costs significantly affect inflation in a number of countries, including France, Germany and the US which together contribute, on average, to almost three quarters of the total GVA across the sample countries. The combination of $\lambda^{b}<\lambda^{f}$ and statistically significant real marginal costs in Table 3 indicates that the use of disaggregate data leads to greater support for

\footnotetext{
${ }^{20}$ The largest change in this case occurs when we switch from MG to WMG using aggregate data.

${ }^{21}$ Our MG-FIML estimate of $\lambda^{b}$ for France (0.356) is very close to the corresponding figure reported by IJP for the French representative sector (0.331).
} 
the NKPC model of inflation in general and the notion of dominant forward-looking behavior in particular.

\section{[TABLE 4 HERE]}

Table 4 reports the characteristics of the average sector in each of the sample countries on the basis of WMG-CCE panel estimates. Comparison of the country-specific results in Tables 3 and 4 indicates that WMG-CCE generates considerably lower estimates of inflation persistence. For example, the UK estimate of $\lambda^{b}$ in Table 4 is 0.103 , that is, $62 \%$ lower as compared to its MG-FIML counterpart in Table 3. We should point out that the decline in inflation persistence is driven by the adjustment for cross-sectional correlation. ${ }^{22}$ Regarding the overall fit of the NKPC, the results in Table 4 indicate that the UK should be added to the list of major countries where the model performs well. Particularly, in France, Germany, UK and the US the estimate of $\lambda^{f}$ is around 0.9 , largely exceeding that of $\lambda^{b}$, and the marginal costs' effect on inflation is positive and statistically significant. Nevertheless, the WMG-CCE country-specific results also reveal some instances of negative and statistically significant $\xi$ and/or $\theta$ panel estimates in the remaining countries (see e.g. Greece), which are not supportive of the NKPC model. ${ }^{23}$ As a further robustness check, we examine whether using only country specific averages in the CCE estimation influence the results. If anything, these results are more supportive of the NKPC for a disaggregate approach. For example, the coefficient on labour share $(\theta)$ is positive and significant in nine of the fourteen countries. ${ }^{24}$

\section{[TABLE 5 HERE]}

The sector-specific MG-FIML panel estimates of the hybrid NKPC in Table 5 offer insights into the fit of the model on a sector-by-sector basis. The estimates of $\rho$ are statistically significant

\footnotetext{
${ }^{22}$ This can be seen by comparing the MG-FIML country-specific results in Table 3 with (i) the MG-CCE country-specific results in Table B5 in Appendix B, and (ii) the WMG-FIML country-specific results in Table B4 in Appendix B. The first comparison indicates a large decline in the degree of inflation's backward-looking behaviour when we adjust for cross-sectional correlation. The second comparison suggests that in most sample countries adjusting for GVA based weights leads to moderately higher estimates of inflation persistence. Hence, the decline in the country-specific $\lambda^{b}$ when we switch from MG-FIML to WMG-CCE should be attributed to the adjustment for cross-sectional correlation.

${ }^{23}$ The WMG-FIML country-specific results in Table B4 in Appendix B also reveal a few instances of negative and statistically significant $\xi$ and/or $\theta$ panel estimates. On the other hand, in line with the MG-FIML countryspecific results in Table 3, the MG-CCE country-specific results in Table B5 in Appendix B reveal no case of significantly negative impact from marginal costs on inflation. Therefore, in the few instances where we identify such an impact, it is related to the use of GVA based weights.

${ }^{24}$ Results are presented in Table B6 in Appendix B.
} 
in all cases, ranging from 0.784 in agriculture, hunting and forestry to 0.911 in real estate, renting and business activities. Compared to marginal costs' dynamics, inflation dynamics exhibit more considerable heterogeneity across sectors, with $\lambda^{b}$ estimates reaching a minimum of around 0.1 in agriculture, hunting and forestry, and fishing while the maximum value is 0.365 in health and social work. Another sector characterized by high inflation persistence is public administration, defence and compulsory social security. Finally, while $\lambda^{b}<\lambda^{f}$ in all cases, the effect of marginal costs on inflation is not statistically significant for the majority of the sample sectors. Furthermore, out of the three sectors which are economically important in terms of their contribution to the national GVA across the sample countries, only in total manufacturing is the closed-form solution estimate of the relationship between inflation and marginal costs significant.

\section{[TABLE 6 HERE]}

Much stronger support for the importance of forward-looking expectations in price setting is provided by the WMG-CCE panel estimates in Table 6. Specifically, not only do we obtain positive and statistically significant estimates of $\xi$ and/or $\theta$ in most cases, but also the estimates of the degree of backward-looking behavior are substantially lower, as compared to those in Table 5. For example, the estimate of $\lambda^{b}$ for the wholesale and retail trade sector displays a very large decline (from 0.296 to 0.071). At the same time marginal costs become significant when we switch from MG-FIML to WMG-CCE. Similar findings are obtained for real estate, renting and business activities, another economically important service sector. It should be noted that the improvement in the marginal costs' significance can be attributed to the the weighting scheme, as opposed to the adjustment for cross-sectional correlation. ${ }^{25}$ Table 6 also reveals a few instances of significantly negative relationship, or no relationship at all, between marginal costs and inflation. In contrast to the MG-FIML results in Table 5, total manufacturing is one of the sectors where the estimated $\xi$ is significantly negative. Thus, overall, the WMG-CCE results imply that the NKPC model works well in the majority of the sectors, including two out of the three of the most important sectors. ${ }^{26}$

\footnotetext{
${ }^{25}$ Particularly, examination of the WMG-FIML and MG-CCE sector-specific results in Tables B8 and B9, respectively, in Appendix B reveals that in the former there are 10 instances of positive and significant $\theta$ 's, as compared to a single case (mining and quarrying) in the latter. On the other hand, as in the country-specific results, the reduction in inflation persistence in the sector-specific results can be attributed to the adjustment for cross-sectional correlation. Specifically, sector-specific estimates of $\lambda^{b}$ decline significantly when CCE, as opposed to FIML, is used, but remain largely unchanged when WMG, as opposed to $\mathrm{MG}$, is used.

${ }^{26}$ Using the alternative approach to calculate the CCE factors, there is even stronger support for the NKPC. See Table B7 in Appendix B.
} 


\section{Conclusions}

There is a nascent theoretical literature which emphasizes the importance of heterogeneity in inflation dynamics. Sheedy (2007) suggests that the assumption of homogeneous inflation dynamics in not innocuous and highlights that inflation persistence is lower once we account for heterogeneity in price stickiness. Carvalho (2006) suggests that monetary policy shocks are larger and more persistent in heterogeneous economies. Related to the previous point, Leith and Malley (2007) point out that monetary policymakers should be concerned since sectoral differences in pricing behaviour also imply significant sectoral differences in reponse to monetary policy. Finally, IJP suggest that using sectoral NKPC estimates in a calibration exercise produces sizable differences in the response of output and inflation and they argue that heterogeneity can have welfare implications.

Nevertheless, only a few studies have attempted to estimate the NKPC using sectoral data. This paper makes a significant contribution to this emerging literature. We emphasize that it is important to examine disaggregate inflation data and to utilize the appropriate estimation approach. Our results from time-series and panel estimation techniques suggest that sector-level heterogeneity has important consequences for the aggregate. Heterogeneity helps to explain the over (under) estimation of the the degree of backward-looking behavior (impact of marginal costs) in empirical investigations of the NKPC that use aggregate data. Specifically, while aggregate data estimates suggest a weak impact from real marginal costs on inflation, our disaggregate estimates generally provide stronger evidence for the theoretical role of marginal costs, while at the same time the estimated inflation persistence is reduced. Hence, our results indicate that an empirical approach which combines disaggregate information with heterogeneous-consistent estimation techniques helps to reconcile to a great extent the NKPC with the data and reverse the biases imposed by approaches that ignore heterogeneity. However, it should be added that the results can be country-specific. While the evidence is not very supportive for the NKPC in some of the smaller countries in our dataset, the model does well to explain inflation in the US, UK, Germany and France. Given that the data are qualitatively similar and harmonized across countries, we could conjecture that a plausible explanation for this dichotomy is related to the assumptions underlying the NKPC. Particularly, it might be the case that in the smaller countries either the assumption of monopolistic competition and/or the notion that firms set prices only considering the labour share of income are not fully satisfied. This dichotomy between small and big countries provides fertile ground for further research. 


\section{References}

Altissimo, F., Bilke, L., Levin, A., Math, T., and Mojon, B., 2006. Sectoral and aggregate inflation dynamics in the Euro area, Journal of the European Economic Association, 4 (2-3), $585-593$.

Altissimo, F., Mojon, B., and Zaffaroni, P., 2007. Fast micro und slow macro: can aggregation explain the persistence of inflation?, Working Paper Series 729, European Central Bank.

Arellano, M. and Bond, S., 1991. Some tests of specification for panel data: Monte carlo evidence and an application to employment equations, Review of Economic Studies, 58 (2), 277-97.

Bardsen, G., Jansen, E.S., and Nymoen, R., 2004. Econometric evaluation of the New Keynesian Phillips curve, Oxford Bulletin of Economics and Statistics, 66 (s1), 671-686.

Benigno, P. and Lopez-Salido, J.D., 2006. Inflation persistence and optimal monetary policy in the euro area, Journal of Money, Credit and Banking, 38 (3), 587-614.

Bils, M. and Klenow, P.J., 2004. Some evidence on the importance of sticky prices, Journal of Political Economy, 112 (5), 947-985.

Byrne, J.P., Kontonikas, A., and Montagnoli, A., 2010. The time-series properties of UK inflation: Evidence from aggregate and disaggregate data, Scottish Journal of Political Economy, 57 (1), 33-47.

Calvo, G.A., 1983. Staggered prices in a utility-maximizing framework, Journal of Monetary Economics, 12 (3), 383-398.

Carvalho, C., 2006. Heterogeneity in price stickiness and the real effects of monetary shocks, The B.E. Journal of Macroeconomics, 2 (1), 1-56.

Christiano, L.J., Eichenbaum, M., and Evans, C.L., 2005. Nominal rigidities and the dynamic effects of a shock to monetary policy, Journal of Political Economy, 113 (1), 1-45.

Clark, T.E., 2006. Disaggregate evidence on the persistence of consumer price inflation, Journal of Applied Econometrics, 21 (5), 563-587.

Dees, S., Pesaran, M.H., Smith, L.V., and Smith, R.P., 2009. Identification of new keynesian phillips curves from a global perspective, Journal of Money, Credit and Banking, 41 (7), 1481-1502. 
Dhyne, E., lvarez, L.J., Bihan, H.L., Veronese, G., Dias, D., Hoffmann, J., Jonker, N., Lnnemann, P., Rumler, F., and Vilmunen, J., 2005. Price setting in the Euro area: some stylized facts from individual consumer price data, Working Paper Series 524, European Central Bank.

Dufour, J.M., Khalaf, L., and Kichian, M., 2006. Inflation dynamics and the New Keynesian Phillips curve: An identification robust econometric analysis, Journal of Economic Dynamics and Control, 30 (9-10), 1707-1727.

Fuhrer, J.C., Moore, G.R., and Schuh, S.D., 1995. Estimating the linear-quadratic inventory model maximum likelihood versus generalized method of moments, Journal of Monetary Economics, 35 (1), 115-157.

Gali, J. and Gertler, M., 1999. Inflation dynamics: A structural econometric analysis, Journal of Monetary Economics, 44 (2), 195-222.

Gali, J., Gertler, M., and Lopez-Salido, J.D., 2001. European inflation dynamics, European Economic Review, 45 (7), 1237-1270.

Hsiao, C. and Pesaran, M.H., 2008. Random coefficient models, in: L. Matyas and E. Patrick Sevestre, eds., The Econometrics of Panel Data: Fundamentals and Recent Developments in Theory and Practice (Advanced Studies in Theoretical and Applied Econometrics), Springler, $185-213$.

Hsiao, C., Pesaran, M.H., and Tahmiscioglu, A.K., 1999. Bayes estimation of short-run coefficients in dynamic panel data models, in: K.L. Cheng Hsiao, M. Hashem Pesaran and E. Lung Fei Lee, eds., Analysis of Panels and Limited Dependent Variables Models, Cambridge: Cambridge University Press, 268-296.

Imbs, J., Jondeau, E., and Pelgrin, F., 2007. Aggregating Phillips curves, CEPR Discussion Papers 6184, C.E.P.R. Discussion Papers.

Imbs, J., Jondeau, E., and Pelgrin, F., 2009. Sectoral Phillips curves and the aggregate Phillips curve, mimeo.

Jondeau, E. and Le Bihan, H., 2008. Examining bias in estimators of linear rational expectations models under misspecification, Journal of Econometrics, 143 (2), 375-395.

Jondeau, E. and Pelgrin, F., 2009. Aggregating rational expectations models in the presence of unobserved micro heterogeneity, Swiss Finance Institute Research Paper Series 09-30, Swiss Finance Institute. 
Kurmann, A., 2007. Var-based estimation of euler equations with an application to new keynesian pricing, Journal of Economic Dynamics and Control, 31 (3), 767-796.

Lawless, M. and Whelan, K., 2007. Understanding the dynamics of labor shares and inflation, Working Paper Series 784, European Central Bank.

Leith, C. and Malley, J., 2007. A sectoral analysis of price-setting behavior in U.S. manufacturing industries, The Review of Economics and Statistics, 89 (2), 335-342.

Linde, J., 2005. Estimating New-Keynesian Phillips curves: A full information maximum likelihood approach, Journal of Monetary Economics, 52 (6), 1135-1149.

Nakamura, E. and Steinsson, J., 2008. Five facts about prices: A reevaluation of menu cost models, The Quarterly Journal of Economics, 123 (4), 1415-1464.

Nason, J.M. and Smith, G.W., 2008. Identifying the new Keynesian Phillips curve, Journal of Applied Econometrics, 23 (5), 525-551.

Pesaran, M., Smith, R.P., and Im, K., 1996. Dynamic linear models for heterogeneous panels, in: L. Matyas and E. Patrick Sevestre, eds., The Econometrics of Panel Data A Handbook of the Theory and Applications, Springer, 145-195.

Pesaran, M.H., 2006. Estimation and inference in large heterogeneous panels with a multifactor error structure, Econometrica, 74 (4), 967-1012.

Pesaran, M.H. and Smith, R., 1995. Estimating long-run relationships from dynamic heterogeneous panels, Journal of Econometrics, 68 (1), 79-113.

Rudd, J. and Whelan, K., 2005. New tests of the New-Keynesian Phillips curve, Journal of Monetary Economics, 52 (6), 1167-1181.

Rudd, J. and Whelan, K., 2006. Can rational expectations sticky-price models explain inflation dynamics?, American Economic Review, 96 (1), 303-320.

Rudd, J. and Whelan, K., 2007. Modeling inflation dynamics: A critical review of recent research, Journal of Money, Credit and Banking, 39 (s1), 155-170.

Sbordone, A.M., 2002. Prices and unit labor costs: a new test of price stickiness, Journal of Monetary Economics, 49 (2), 265-292.

Sheedy, K.D., 2007. Inflation persistence when price stickiness differs between industries, CEP Discussion Papers dp0838, Centre for Economic Performance, LSE. 
Stock, J.H., Wright, J.H., and Yogo, M., 2002. A survey of weak instruments and weak identification in generalized method of moments, Journal of Business 83 Economic Statistics, 20 (4), $518-29$.

van Ark, B., O'Mahoney, M., and Timmer, M.P., 2008. The productivity gap between Europe and the United States: Trends and causes, Journal of Economic Perspectives, 22 (1), 25-44.

Walsh, C., 2010. Monetary Theory and Policy, The MIT Press, 3rd ed.

Woodford, M., 2003. Interest and Prices: Foundations of a Theory of Monetary Policy, Princeton University Press. 
Table 1: NKPC Aggregate Time Series Estimates

\begin{tabular}{lcccccc}
\hline \hline Country & $\delta$ & $\xi$ & $\rho$ & $\lambda^{b}$ & $\lambda^{f}$ & $\theta$ \\
\hline \hline Austria & 0.116 & $\mathbf{0 . 1 9 3}$ & $\mathbf{0 . 9 5}$ & 0.104 & 0.896 & 0.009 \\
Belgium & $\mathbf{0 . 7 2 3}$ & -0.201 & $\mathbf{0 . 7 8 9}$ & $\mathbf{0 . 4 2 0}$ & $\mathbf{0 . 5 8 0}$ & -0.025 \\
Denmark & $\mathbf{0 . 8 4 6}$ & 0.149 & $\mathbf{0 . 8 0 2}$ & $\mathbf{0 . 4 5 8}$ & $\mathbf{0 . 5 4 2}$ & 0.016 \\
France & $\mathbf{0 . 5 7 4}$ & $\mathbf{0 . 2 3 7}$ & $\mathbf{0 . 9 7 7}$ & $\mathbf{0 . 3 6 5}$ & $\mathbf{0 . 6 3 5}$ & 0.004 \\
Germany & $\mathbf{0 . 4 1 2}$ & 0.22 & $\mathbf{1 . 0 1 8}$ & $\mathbf{0 . 2 9 2}$ & $\mathbf{0 . 7 0 8}$ & -0.003 \\
Greece & $\mathbf{0 . 6 9}$ & $\mathbf{0 . 3 4 9}$ & $\mathbf{0 . 9 3 8}$ & $\mathbf{0 . 4 0 8}$ & $\mathbf{0 . 5 9 2}$ & 0.013 \\
Ireland & $\mathbf{0 . 5 8 3}$ & 0.195 & $\mathbf{0 . 9 7 0}$ & $\mathbf{0 . 3 6 8}$ & $\mathbf{0 . 6 3 2}$ & 0.004 \\
Italy & $\mathbf{0 . 7 7 2}$ & 0.153 & $\mathbf{0 . 9 8 4}$ & $\mathbf{0 . 4 3 6}$ & $\mathbf{0 . 5 6 4}$ & 0.001 \\
Netherlands & $\mathbf{0 . 7 5 8}$ & 0.076 & $\mathbf{0 . 9 6 7}$ & $\mathbf{0 . 4 3 1}$ & $\mathbf{0 . 5 6 9}$ & 0.001 \\
Portugal & $\mathbf{0 . 8 6 4}$ & -0.245 & $\mathbf{0 . 7 2 4}$ & $\mathbf{0 . 4 6 4}$ & $\mathbf{0 . 5 3 6}$ & -0.036 \\
Spain & $\mathbf{0 . 7 6 7}$ & 0.272 & $\mathbf{0 . 9 8 3}$ & $\mathbf{0 . 4 3 4}$ & $\mathbf{0 . 5 6 6}$ & 0.003 \\
Sweden & $\mathbf{0 . 6 9 8}$ & 0.166 & $\mathbf{0 . 9 2 9}$ & $\mathbf{0 . 4 1 1}$ & $\mathbf{0 . 5 8 9}$ & 0.007 \\
UK & $\mathbf{0 . 7 8 5}$ & -0.212 & $\mathbf{0 . 6 0 5}$ & $\mathbf{0 . 4 4 0}$ & $\mathbf{0 . 5 6 0}$ & -0.047 \\
USA & $\mathbf{0 . 7 0 4}$ & 1.455 & $\mathbf{0 . 4 5}$ & $\mathbf{0 . 4 1 3}$ & $\mathbf{0 . 5 8 7}$ & 0.47 \\
\hline \hline
\end{tabular}

Notes: This table shows the Full Information Maximum Likelihood (FIML) time-series estimation results using aggregate data. The frequency of the variables in our dataset is annual and the sample period is 1971-2005 $(\mathrm{T}=35)$. Estimates in bold indicate statistical significance at the $5 \%$ level.

Table 2: NKPC Aggregate and Disaggregate Estimates

\begin{tabular}{ccc|cc|cc|cc}
\hline \hline & \multicolumn{2}{c}{ MG-FIML } & \multicolumn{2}{c}{ WMG-FIML } & \multicolumn{2}{c}{ MG-CCE } & \multicolumn{2}{c}{ WMG-CCE } \\
\hline & Agg & Disagg & Agg & Disagg & Agg & Disagg & Agg & Disagg \\
\hline$\delta$ & $\mathbf{0 . 6 6 4}$ & $\mathbf{0 . 4 2 3}$ & $\mathbf{0 . 6 7 1}$ & $\mathbf{0 . 4 0 0}$ & $\mathbf{0 . 3 4 3}$ & $\mathbf{0 . 1 4 8}$ & $\mathbf{0 . 2 3 0}$ & $\mathbf{0 . 1 2 9}$ \\
$\xi$ & 0.200 & $\mathbf{0 . 0 7 7}$ & $\mathbf{0 . 8 2 0}$ & $\mathbf{0 . 1 2 5}$ & 0.058 & 0.029 & $\mathbf{0 . 3 1 0}$ & $\mathbf{0 . 1 0 6}$ \\
$\rho$ & $\mathbf{0 . 8 6 3}$ & $\mathbf{0 . 8 6 3}$ & $\mathbf{0 . 6 7 1}$ & $\mathbf{0 . 8 4 9}$ & $\mathbf{0 . 7 2 3}$ & $\mathbf{0 . 8 0 5}$ & $\mathbf{0 . 5 7 5}$ & $\mathbf{0 . 7 9 5}$ \\
$\lambda^{b}$ & $\mathbf{0 . 3 8 9}$ & $\mathbf{0 . 2 7 2}$ & $\mathbf{0 . 3 9 8}$ & $\mathbf{0 . 2 5 4}$ & $\mathbf{0 . 2 1 7}$ & $\mathbf{0 . 0 9 1}$ & $\mathbf{0 . 1 7 6}$ & $\mathbf{0 . 0 8 7}$ \\
$\lambda^{f}$ & $\mathbf{0 . 6 1 1}$ & $\mathbf{0 . 7 2 8}$ & $\mathbf{0 . 6 0 2}$ & $\mathbf{0 . 7 4 6}$ & $\mathbf{0 . 7 8 3}$ & $\mathbf{0 . 9 0 9}$ & $\mathbf{0 . 8 2 4}$ & $\mathbf{0 . 9 1 3}$ \\
$\theta$ & 0.030 & $\mathbf{0 . 0 1 3}$ & $\mathbf{0 . 2 4 1}$ & $\mathbf{0 . 0 3 1}$ & 0.019 & 0.010 & $\mathbf{0 . 1 3 7}$ & $\mathbf{0 . 0 3 9}$ \\
\hline \hline
\end{tabular}

Notes:This table shows the Mean Group (MG) and Weighted Mean Group (WMG) panel estimates of the hybrid NKPC using aggregate and disaggregate data. These are obtained by averaging the individual Full Information Maximum Likelihood (FIML) and Constant Correlated Effect (CCE) time-series estimation results. In the aggregate data case the number of cross-sections $(\mathrm{N})$ is equal to 14 (countries), while in the disaggregate data case $\mathrm{N}=210$ (= 14 (countries) $\mathrm{x} 15$ (sectors)). The frequency of the variables in our dataset is annual and the sample period is 1971-2005 $(\mathrm{T}=35)$. The Gross Value Added (GVA) based weights used for WMG in the case of aggregate data can be seen in Table B2-Panel B in Appendix B. They are calculated by dividing the average national GVA by the sum of the average national GVAs across the sample countries. The weights used for WMG in the case of disaggregate data are calculated by dividing the average sectoral GVA of the given country by the sum of the average national GVAs across the sample countries. The GVAs are expressed in common terms using 1997 German currency PPPs. Estimates in bold indicate statistical significance at the $5 \%$ level. 
Table 3: NKPC Country Disaggregate MG-FIML Estimates

\begin{tabular}{lcccccc}
\hline \hline Country & $\delta$ & $\xi$ & $\rho$ & $\lambda^{b}$ & $\lambda^{f}$ & $\theta$ \\
\hline \hline Austria & $\mathbf{0 . 2 0 4}$ & 0.060 & $\mathbf{0 . 8 8 3}$ & $\mathbf{0 . 1 2 5}$ & $\mathbf{0 . 8 7 5}$ & 0.000 \\
Belgium & $\mathbf{0 . 3 8 3}$ & 0.015 & $\mathbf{0 . 8 2 4 0}$ & $\mathbf{0 . 1 2 2}$ & $\mathbf{0 . 8 7 8}$ & -0.032 \\
Denmark & $\mathbf{0 . 3 7 5}$ & 0.085 & $\mathbf{0 . 8 2 3}$ & $\mathbf{0 . 2 4 9}$ & $\mathbf{0 . 7 5 1}$ & 0.023 \\
France & $\mathbf{0 . 6 0 1}$ & $\mathbf{0 . 1 2 4}$ & $\mathbf{0 . 8 7 8}$ & $\mathbf{0 . 3 5 6}$ & $\mathbf{0 . 6 4 4}$ & $\mathbf{0 . 0 0 9}$ \\
Germany & $\mathbf{0 . 3 3 8}$ & $\mathbf{0 . 1 5 1}$ & $\mathbf{0 . 8 3 7}$ & $\mathbf{0 . 2 2 7}$ & $\mathbf{0 . 7 7 3}$ & $\mathbf{0 . 0 5 7}$ \\
Greece & $\mathbf{0 . 4 6 5}$ & 0.099 & $\mathbf{0 . 8 7 0}$ & $\mathbf{0 . 3 0 8}$ & $\mathbf{0 . 6 9 2}$ & 0.025 \\
Ireland & $\mathbf{0 . 4 7 9}$ & -0.081 & $\mathbf{0 . 8 8 2}$ & $\mathbf{0 . 3 1 3}$ & $\mathbf{0 . 6 8 7}$ & -0.014 \\
Italy & $\mathbf{0 . 5 1 1}$ & $\mathbf{0 . 0 6 6}$ & $\mathbf{0 . 8 3 5}$ & $\mathbf{0 . 3 1 4}$ & $\mathbf{0 . 6 8 6}$ & -0.004 \\
Netherlands & $\mathbf{0 . 4 7 4}$ & -0.018 & $\mathbf{0 . 8 9 6}$ & $\mathbf{0 . 2 9 4}$ & $\mathbf{0 . 7 0 6}$ & -0.001 \\
Portugal & $\mathbf{0 . 4 7 4}$ & $\mathbf{0 . 2 1 5}$ & $\mathbf{0 . 8 7 6}$ & $\mathbf{0 . 3 1 0 3}$ & $\mathbf{0 . 6 8 7}$ & $\mathbf{0 . 0 1 9}$ \\
Spain & $\mathbf{0 . 5 2 0}$ & 0.047 & $\mathbf{0 . 9 0 6}$ & $\mathbf{0 . 3 2 4}$ & $\mathbf{0 . 6 7 6}$ & 0.001 \\
Sweden & $\mathbf{0 . 3 9 1}$ & $\mathbf{0 . 1 9 9}$ & $\mathbf{0 . 8 6 1}$ & $\mathbf{0 . 2 6 1}$ & $\mathbf{0 . 7 3 9}$ & $\mathbf{0 . 0 2 4}$ \\
UK & $\mathbf{0 . 4 0 0}$ & -0.023 & $\mathbf{0 . 8 9 1}$ & $\mathbf{0 . 2 7 0}$ & $\mathbf{0 . 7 3 0}$ & 0.019 \\
USA & $\mathbf{0 . 2 9 3}$ & $\mathbf{0 . 2 1 3}$ & $\mathbf{0 . 8 0 4}$ & $\mathbf{0 . 1 9 5}$ & $\mathbf{0 . 8 0 5}$ & $\mathbf{0 . 0 5 5}$ \\
\hline \hline
\end{tabular}

Notes: This table shows the country-specific Mean Group (MG)-Full Information Maximum Likelihood (FIML) panel estimates of the hybrid NKPC using disaggregate data. These are obtained by averaging the disaggregate FIML time-series estimation results across the $15(=\mathrm{N})$ sample sectors in a per-country basis (e.g. German agriculture, hunting and forestry, German construction, etc). The frequency of the variables in our dataset is annual and the sample period is 1971-2005 ( $\mathrm{T}=35)$. Estimates in bold indicate statistical significance at the 5\% level.

Table 4: NKPC Country Disaggregate WMG-CCE Estimates

\begin{tabular}{lcccccc}
\hline \hline Country & $\delta$ & $\xi$ & $\rho$ & $\lambda^{b}$ & $\lambda^{f}$ & $\theta$ \\
\hline \hline Austria & -0.036 & -0.020 & $\mathbf{0 . 8 2 0}$ & $\mathbf{- 0 . 1 5 8}$ & $\mathbf{1 . 1 5 8}$ & -0.0056 \\
Belgium & $\mathbf{0 . 1 3 9}$ & -0.012 & $\mathbf{0 . 8 5 9}$ & $\mathbf{0 . 0 9 9}$ & $\mathbf{0 . 9 0 0}$ & -0.0015 \\
Denmark & $\mathbf{0 . 1 0 7}$ & $\mathbf{0 . 1 1 5}$ & $\mathbf{0 . 7 4 4}$ & $\mathbf{0 . 0 4 1}$ & $\mathbf{0 . 9 5 8}$ & $\mathbf{0 . 0 4 1}$ \\
France & $\mathbf{0 . 1 4 4}$ & $\mathbf{0 . 0 6 1}$ & $\mathbf{0 . 8 6 8}$ & $\mathbf{0 . 1 0 0}$ & $\mathbf{0 . 8 9 9}$ & $\mathbf{0 . 0 1 1}$ \\
Germany & $\mathbf{0 . 1 6 1}$ & $\mathbf{0 . 1 2 3}$ & $\mathbf{0 . 8 7 4}$ & $\mathbf{0 . 1 1 5}$ & $\mathbf{0 . 8 8 4}$ & $\mathbf{0 . 0 4 1}$ \\
Greece & $\mathbf{0 . 4 1 1}$ & $\mathbf{- 0 . 0 8 0}$ & $\mathbf{0 . 8 2 5}$ & $\mathbf{0 . 2 8 5}$ & $\mathbf{0 . 7 1 9}$ & $\mathbf{- 0 . 0 1 1}$ \\
Ireland & -0.037 & $\mathbf{0 . 0 8 6 7}$ & $\mathbf{0 . 8 6 9}$ & $\mathbf{- 0 . 0 5 5}$ & $\mathbf{1 . 0 5 5}$ & 0.003 \\
Italy & $\mathbf{0 . 1 1 8}$ & 0.004 & $\mathbf{0 . 7 2 9}$ & $\mathbf{0 . 0 7 0}$ & $\mathbf{0 . 9 2 9}$ & 0.004 \\
Netherlands & $\mathbf{0 . 4 2 0}$ & $\mathbf{- 0 . 1 1 0}$ & $\mathbf{0 . 8 5 8}$ & $\mathbf{0 . 2 6 0}$ & $\mathbf{0 . 7 3 9}$ & 0.003 \\
Portugal & $\mathbf{0 . 2 6 6}$ & $\mathbf{- 0 . 1 0 1}$ & $\mathbf{0 . 8 4 5}$ & $\mathbf{0 . 1 7 1}$ & $\mathbf{0 . 8 2 8}$ & $\mathbf{- 0 . 0 0 7}$ \\
Spain & $\mathbf{0 . 2 4 5}$ & $\mathbf{- 0 . 0 4 5}$ & $\mathbf{0 . 9 1 1}$ & $\mathbf{0 . 1 8 1}$ & $\mathbf{0 . 8 1 8}$ & 0.000 \\
Sweden & $\mathbf{0 . 1 2 3}$ & -0.033 & $\mathbf{0 . 7 5 7}$ & $\mathbf{0 . 0 8 7}$ & $\mathbf{0 . 9 1 2}$ & -0.008 \\
UK & $\mathbf{0 . 1 2 7}$ & $\mathbf{0 . 1 1 1}$ & $\mathbf{0 . 8 0 1}$ & $\mathbf{0 . 1 0 3}$ & $\mathbf{0 . 8 9 6}$ & $\mathbf{0 . 0 3 4}$ \\
USA & $\mathbf{0 . 0 9 8}$ & $\mathbf{0 . 1 6 8}$ & $\mathbf{0 . 7 4 9}$ & $\mathbf{0 . 0 6 7}$ & $\mathbf{0 . 9 3 2}$ & $\mathbf{0 . 0 6 1}$ \\
\hline \hline
\end{tabular}

Notes:This table shows the country-specific Weighted Mean Group (WMG)-Constant Correlated Effect (CCE) panel estimates of the hybrid NKPC using disaggregate data. These are obtained by averaging the disaggregate CCE time-series estimation results across the $15(=\mathrm{N})$ sample sectors in a per-country basis (e.g. German agriculture, hunting and forestry, German construction, etc). The frequency of the variables in our dataset is annual and the sample period is 1971-2005 $(\mathrm{T}=35)$. The Gross Value Added (GVA) based weights used for WMG can be seen in Table B1 in Appendix B. They are calculated by dividing the average sectoral GVA by the average national GVA. Estimates in bold indicate statistical significance at the $5 \%$ level. 
Table 5: NKPC Sectoral Disaggregate MG-FIML Estimates

\begin{tabular}{lcccccc}
\hline \hline Sector & $\delta$ & $\xi$ & $\rho$ & $\lambda^{b}$ & $\lambda^{f}$ & $\theta$ \\
\hline \hline Agriculture, Hunting and Forestry & $\mathbf{0 . 1 7 3}$ & $\mathbf{0 . 1 4 1}$ & $\mathbf{0 . 7 8 4}$ & $\mathbf{0 . 1 1 5}$ & $\mathbf{0 . 8 8 5}$ & $\mathbf{0 . 0 4 7}$ \\
Fishing & $\mathbf{0 . 1 3 6}$ & -0.034 & $\mathbf{0 . 8 1 3}$ & $\mathbf{0 . 0 9 2}$ & $\mathbf{0 . 9 0 8}$ & -0.037 \\
Mining and Quarrying & $\mathbf{0 . 2 8 8}$ & $\mathbf{0 . 1 1 0}$ & $\mathbf{0 . 8 4 4}$ & $\mathbf{0 . 2 1 8}$ & $\mathbf{0 . 7 8 2}$ & $\mathbf{0 . 0 1 9}$ \\
Total Manufacturing & $\mathbf{0 . 4 9 7}$ & $\mathbf{0 . 1 3 9}$ & $\mathbf{0 . 8 8 0}$ & $\mathbf{0 . 3 0 7}$ & $\mathbf{0 . 6 9 3}$ & 0.012 \\
Electricity, Gas and Water Supply & $\mathbf{0 . 3 0 4}$ & $\mathbf{0 . 1 3 5}$ & $\mathbf{0 . 8 7 9}$ & $\mathbf{0 . 2 2 2}$ & $\mathbf{0 . 7 7 8}$ & 0.019 \\
Construction & $\mathbf{0 . 5 0 8}$ & -0.068 & $\mathbf{0 . 8 0 8}$ & $\mathbf{0 . 3 1 4}$ & $\mathbf{0 . 6 8 6}$ & -0.003 \\
Whosale and Retail Trade & $\mathbf{0 . 4 8 5}$ & 0.053 & $\mathbf{0 . 8 3 2}$ & $\mathbf{0 . 2 9 6}$ & $\mathbf{0 . 7 0 4}$ & -0.007 \\
Hotels and Restaurants & $\mathbf{0 . 4 2 0}$ & 0.082 & $\mathbf{0 . 8 5 2}$ & $\mathbf{0 . 2 7 2}$ & $\mathbf{0 . 7 2 8}$ & 0.004 \\
Transport, Storage and Communication & $\mathbf{0 . 4 3 2}$ & 0.180 & $\mathbf{0 . 9 0 1}$ & $\mathbf{0 . 2 8 0}$ & $\mathbf{0 . 7 2 0}$ & 0.010 \\
Financial Intermediation & $\mathbf{0 . 3 4 5}$ & $\mathbf{0 . 2 8 2}$ & $\mathbf{0 . 8 0 0}$ & $\mathbf{0 . 2 4 1}$ & $\mathbf{0 . 7 5 9}$ & 0.078 \\
Real Estate, Renting and Business Act. & $\mathbf{0 . 5 3 1}$ & -0.009 & $\mathbf{0 . 9 4 2}$ & $\mathbf{0 . 3 3 1}$ & $\mathbf{0 . 6 6 9}$ & 0.003 \\
Public Admin., Def. and Comp. Soc. Sec. & $\mathbf{0 . 5 9 2}$ & 0.150 & $\mathbf{0 . 9 3 4}$ & $\mathbf{0 . 3 6 2}$ & $\mathbf{0 . 6 3 8}$ & $\mathbf{0 . 0 4 3}$ \\
Education & $\mathbf{0 . 5 2 3}$ & -0.205 & $\mathbf{0 . 8 9 8}$ & $\mathbf{0 . 3 2 2}$ & $\mathbf{0 . 6 7 8}$ & -0.009 \\
Health and Social Work & $\mathbf{0 . 5 8 7}$ & 0.032 & $\mathbf{0 . 8 6 1}$ & $\mathbf{0 . 3 6 5}$ & $\mathbf{0 . 6 3 5}$ & 0.000 \\
Other Community, Social and Pers. Serv. & $\mathbf{0 . 5 1 8}$ & $\mathbf{0 . 1 5 9}$ & $\mathbf{0 . 9 1 1}$ & $\mathbf{0 . 3 3 6}$ & $\mathbf{0 . 6 6 4}$ & 0.015 \\
\hline \hline
\end{tabular}

Notes:This table shows the sector-specific Mean Group (MG)-Full Information Maximum Likelihood (FIML) panel estimates of the hybrid NKPC using disaggregate data. These are obtained by averaging the disaggregate FIML time-series estimation results across the $14(=\mathrm{N})$ sample countries in a persector basis (e.g. French construction, German construction, etc). The frequency of the variables in our dataset is annual and the sample period is 1971-2005 ( $\mathrm{T}=35$ ). Estimates in bold indicate statistical significance at the $5 \%$ level.

Table 6: NKPC Sectoral Disaggregate WMG-CCE Estimates

\begin{tabular}{lcccccc}
\hline \hline Sector & $\delta$ & $\xi$ & $\rho$ & $\lambda^{b}$ & $\lambda^{f}$ & $\theta$ \\
\hline \hline Agriculture, Hunting and Forestry & $\mathbf{- 0 . 0 7 6}$ & $\mathbf{0 . 4 5 1}$ & $\mathbf{0 . 6 8 5}$ & $\mathbf{- 0 . 0 9 5}$ & $\mathbf{1 . 0 9 5}$ & $\mathbf{0 . 2 1 7}$ \\
Fishing & $\mathbf{0 . 1 2 4}$ & $\mathbf{0 . 0 5 9}$ & $\mathbf{0 . 7 7 6}$ & $\mathbf{0 . 0 7 6}$ & $\mathbf{0 . 9 2 4}$ & 0.003 \\
Mining and Quarrying & $\mathbf{0 . 2 5 6}$ & $\mathbf{0 . 2 8 6}$ & $\mathbf{0 . 8 0 7}$ & $\mathbf{0 . 1 9 7}$ & $\mathbf{0 . 8 0 3}$ & $\mathbf{0 . 0 4 3}$ \\
Total Manufacturing & $\mathbf{0 . 0 6 0}$ & $\mathbf{- 0 . 0 4 3}$ & $\mathbf{0 . 8 6 8}$ & $\mathbf{0 . 0 4 0}$ & $\mathbf{0 . 9 6 0}$ & -0.002 \\
Electricity, Gas and Water Supply & -0.005 & $\mathbf{- 0 . 1 1 4}$ & $\mathbf{0 . 8 2 2}$ & -0.011 & $\mathbf{1 . 0 1 1}$ & $\mathbf{- 0 . 0 2 3}$ \\
Construction & $\mathbf{0 . 3 8 4}$ & $\mathbf{- 0 . 1 3 1}$ & $\mathbf{0 . 8 2 3}$ & $\mathbf{0 . 2 4 4}$ & $\mathbf{0 . 7 5 6}$ & $\mathbf{- 0 . 0 1 4}$ \\
Whosale and Retail Trade & $\mathbf{0 . 0 9 0}$ & $\mathbf{0 . 0 7 6}$ & $\mathbf{0 . 5 9 9}$ & $\mathbf{0 . 0 7 1}$ & $\mathbf{0 . 9 2 9}$ & $\mathbf{0 . 0 4 4}$ \\
Hotels and Restaurants & $\mathbf{0 . 1 9 4}$ & $\mathbf{0 . 0 9 5}$ & $\mathbf{0 . 8 4 3}$ & $\mathbf{0 . 1 5 3}$ & $\mathbf{0 . 8 4 7}$ & $\mathbf{0 . 0 1 4}$ \\
Transport, Storage and Communication & $\mathbf{0 . 1 9 5}$ & $\mathbf{0 . 1 7 5}$ & $\mathbf{0 . 7 8 1}$ & $\mathbf{0 . 1 3 7}$ & $\mathbf{0 . 8 6 3}$ & $\mathbf{0 . 0 3 9}$ \\
Financial Intermediation & $\mathbf{0 . 0 0 8}$ & $\mathbf{0 . 4 6 1}$ & $\mathbf{0 . 6 8 0}$ & 0.004 & $\mathbf{0 . 9 9 6}$ & $\mathbf{0 . 1 7 3}$ \\
Real Estate, Renting and Business Act. & $\mathbf{0 . 1 1 9}$ & $\mathbf{0 . 0 4 5}$ & $\mathbf{0 . 8 7 3}$ & $\mathbf{0 . 0 7 8}$ & $\mathbf{0 . 9 2 2}$ & $\mathbf{0 . 0 0 8}$ \\
Public Admin., Def. and Comp. Soc. Sec. & $\mathbf{0 . 1 3 7}$ & $\mathbf{0 . 5 3 0}$ & $\mathbf{0 . 7 4 7}$ & $\mathbf{0 . 1 1 2}$ & $\mathbf{0 . 8 8 8}$ & $\mathbf{0 . 1 4 8}$ \\
Education & $\mathbf{0 . 0 7 5}$ & $\mathbf{0 . 0 8 5}$ & $\mathbf{0 . 7 4 8}$ & $\mathbf{0 . 0 4 1}$ & $\mathbf{0 . 9 5 9}$ & $\mathbf{0 . 0 6 4}$ \\
Health and Social Work & $\mathbf{0 . 3 7 0}$ & $\mathbf{0 . 0 4 9}$ & $\mathbf{0 . 8 5 8}$ & $\mathbf{0 . 2 3 7}$ & $\mathbf{0 . 7 6 3}$ & $\mathbf{0 . 0 0 3}$ \\
Other Community, Social and Pers. Serv. & $\mathbf{0 . 1 5 1}$ & 0.004 & $\mathbf{0 . 7 9 4}$ & $\mathbf{0 . 1 1 8}$ & $\mathbf{0 . 8 8 2}$ & $\mathbf{0 . 0 0 1}$ \\
\hline \hline
\end{tabular}

Notes: This table shows the sector-specific Weighted Mean Group (WMG)- Constant Correlated Effect (CCE) panel estimates of the hybrid NKPC using disaggregate data. These are obtained by averaging the disaggregate CCE time-series estimation results across the $14(=\mathrm{N})$ sample countries in a per-sector basis (e.g. French construction, German construction, etc). The frequency of the variables in our dataset is annual and the sample period is 1971-2005 ( $\mathrm{T}=35$ ). The Gross Value Added (GVA) based weights used for WMG can be seen in Table B2-Panel A in Appendix B. They are calculated by dividing the average sectoral GVA of the given country by the sum of the average sectoral GVAs across the sample countries. The GVAs are expressed in common terms using 1997 German currency PPPs. Estimates in bold indicate statistical significance at the $5 \%$ level. 


\section{Appendix A}

This Appendix discusses the underlying econometric model used in this paper. Using the restriction $\lambda_{j}^{f}=1-\lambda_{j}^{b}$, the characteristic polynomial of Eq. (3) is given by:

$$
\left(1-\lambda_{j}^{b} L-\left(1-\lambda_{j}^{b}\right) L^{-1}\right)=0
$$

Where $L$ is the lag operator, $L x_{t}=x_{t-1}$, and $L^{-1}=F$ is the lead operator, $F x_{t}=x_{t+1}$. The roots of the characteristic polynomial are $\delta_{j}=\lambda_{j}^{b} /\left(1-\lambda_{j}^{b}\right)$ and $\delta_{j}^{*}=1$. When $\delta_{j}<1$ and $\left|\rho_{j}\right|<1$ existence of a stationary solution is guaranteed, but sunspot shocks may characterise an infinite number of solutions (Jondeau and Le Bihan, 2008). Disregarding sunspot shocks the fundamental solution is given by:

$$
\pi_{j, t}=\delta_{j} \pi_{j, t-1}+\theta_{j}\left(1+\delta_{j}\right) E_{t} \sum_{k=0}^{\infty} s_{j, t+k}+v_{j, t}
$$

Where $v_{j, t}=\varepsilon_{j, t} /\left(1-\lambda_{j}^{b}\right)$ and $\sigma_{v j}^{2}=E\left(v_{j, t}^{2}\right)=\sigma_{\varepsilon j}^{2} /\left(1-\lambda_{j}^{b}\right)^{2}$.

Under the assumption that marginal costs follow an AR(1) process (see Eq. (4)), the closed form solution shown in Eq. (A2) becomes:

$$
\pi_{j, t}=\delta_{j} \pi_{j, t-1}+\xi_{j} s_{j, t}+v_{j, t}
$$

Where $\xi_{j}=\theta_{j} /\left(1-\lambda_{j}^{b}\right)\left(1-\rho_{j}\right)$.

The closed form solution with AR(1) marginal costs can be written in terms of the hybrid NKPC parameters as follows:

$$
\pi_{j, t}=\frac{\lambda_{j}^{b}}{1-\lambda_{j}^{b}} \pi_{j, t-1}+\frac{\theta_{j}}{\left(1-\lambda_{j}^{b}\right)\left(1-\rho_{j}\right)} s_{j, t}+v_{j, t}
$$


Appendix B 


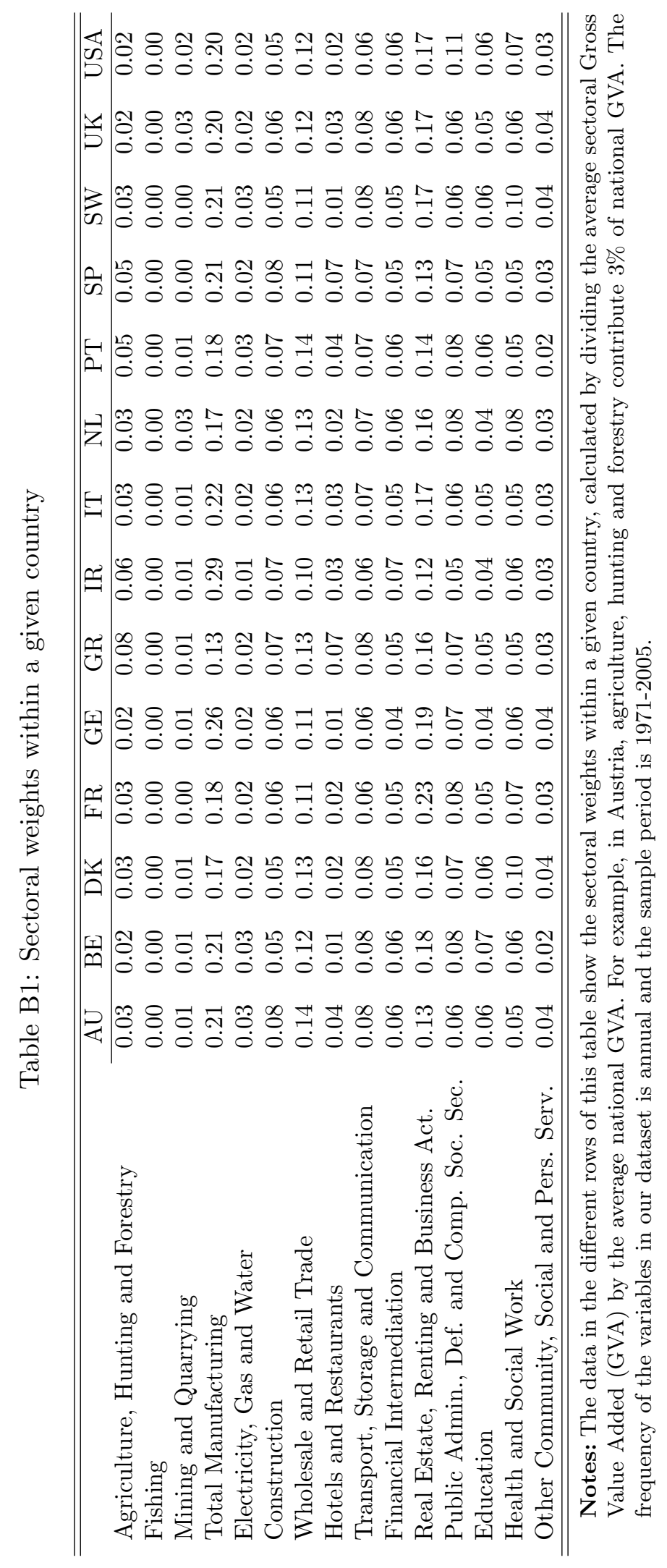




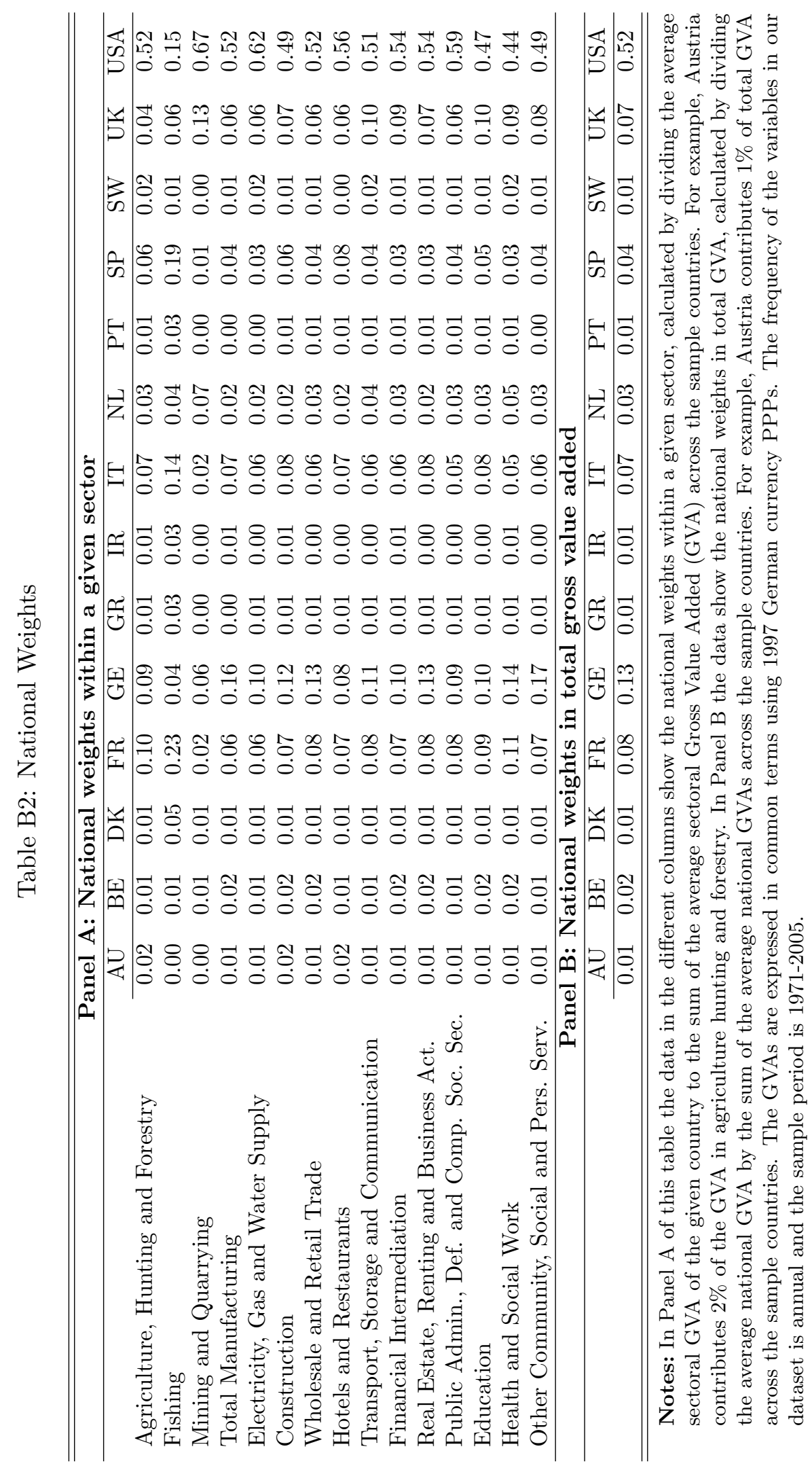


Table B3: Hybrid NKPC time-series estimates, aggregate data, CCE

\begin{tabular}{lcccccc}
\hline \hline & $\delta$ & $\xi$ & $\rho$ & $\lambda^{b}$ & $\lambda^{f}$ & $\theta$ \\
\hline \hline Austria & -0.252 & -0.025 & $\mathbf{0 . 7 5 5}$ & -0.337 & 1.337 & -0.008 \\
Belgium & $\mathbf{0 . 5 8 7}$ & 0.004 & $\mathbf{0 . 8 4 0}$ & $\mathbf{0 . 3 7 0}$ & $\mathbf{0 . 6 3 0}$ & 0.004 \\
Denmark & 0.461 & 0.07 & $\mathbf{0 . 6 4 4}$ & 0.316 & $\mathbf{0 . 6 8 4}$ & 0.017 \\
France & $\mathbf{0 . 2 7 1}$ & 0.141 & $\mathbf{0 . 9 2 4}$ & 0.213 & $\mathbf{0 . 7 8 7}$ & 0.008 \\
Germany & 0.264 & -0.203 & $\mathbf{0 . 5 0 7}$ & $\mathbf{0 . 2 0 9}$ & $\mathbf{0 . 7 9 1}$ & -0.079 \\
Greece & $\mathbf{0 . 6 1 0}$ & 0.164 & $\mathbf{0 . 7 4 9}$ & $\mathbf{0 . 3 7 9}$ & $\mathbf{0 . 6 2 1}$ & 0.026 \\
Ireland & -0.052 & -0.173 & $\mathbf{0 . 8 4 2}$ & -0.055 & $\mathbf{1 . 0 5 5}$ & -0.029 \\
Italys & 0.319 & -0.192 & $\mathbf{0 . 6 3 0}$ & $\mathbf{0 . 2 4 2}$ & $\mathbf{0 . 7 5 8}$ & -0.054 \\
Netherland & $\mathbf{0 . 7 9 3}$ & 0.24 & $\mathbf{0 . 8 3 3}$ & $\mathbf{0 . 4 4 2}$ & $\mathbf{0 . 5 5 8}$ & 0.022 \\
Portugal & $\mathbf{0 . 6 7 4}$ & 0.057 & $\mathbf{0 . 7 5 5}$ & $\mathbf{0 . 4 0 3}$ & $\mathbf{0 . 5 9 7}$ & 0.008 \\
Spain & 0.378 & -0.043 & $\mathbf{0 . 8 3 2}$ & $\mathbf{0 . 2 7 4}$ & $\mathbf{0 . 7 2 6}$ & -0.005 \\
Sweden & 0.367 & -0.175 & $\mathbf{0 . 7 7 1}$ & $\mathbf{0 . 2 6 8}$ & $\mathbf{0 . 7 3 2}$ & -0.029 \\
UK & 0.237 & 0.354 & $\mathbf{0 . 5 5 3}$ & 0.191 & $\mathbf{0 . 8 0 9}$ & 0.128 \\
USA & 0.147 & 0.587 & $\mathbf{0 . 4 8 0}$ & 0.128 & $\mathbf{0 . 8 7 2}$ & 0.266 \\
\hline \hline
\end{tabular}

Notes: This table shows the Constant Correlated Effect (CCE) timeseries estimation results using aggregate data. The frequency of the variables in our dataset is annual and the sample period is 1971-2005 $(\mathrm{T}=35)$. Estimates in bold indicate statistical significance at the $5 \%$ level.

Table B4: Hybrid NKPC panel estimates, disaggregate data, country-specific WMG-FIML

\begin{tabular}{lcccccc}
\hline \hline Country & $\delta$ & $\xi$ & $\rho$ & $\lambda^{b}$ & $\lambda^{f}$ & $\theta$ \\
\hline \hline Austria & $\mathbf{0 . 1 7 2}$ & 0.024 & $\mathbf{0 . 8 9 8}$ & $\mathbf{0 . 0 9 1}$ & $\mathbf{0 . 9 0 9}$ & $\mathbf{- 0 . 0 2 6}$ \\
Belgium & $\mathbf{0 . 4 1 7}$ & $\mathbf{- 0 . 0 6 3}$ & $\mathbf{0 . 8 8 4}$ & $\mathbf{0 . 2 8 4}$ & $\mathbf{0 . 7 1 6}$ & $\mathbf{- 0 . 0 0 5}$ \\
Denmark & $\mathbf{0 . 4 5 3}$ & $\mathbf{0 . 0 7 1}$ & $\mathbf{0 . 8 4 6}$ & $\mathbf{0 . 2 9 2}$ & $\mathbf{0 . 7 0 8}$ & $\mathbf{0 . 0 1 9}$ \\
France & $\mathbf{0 . 6 5 0}$ & $\mathbf{0 . 1 0 9}$ & $\mathbf{0 . 8 8 0}$ & $\mathbf{0 . 3 8 0}$ & $\mathbf{0 . 6 2 0}$ & $\mathbf{0 . 0 0 5}$ \\
Germany & $\mathbf{0 . 3 6 3}$ & 0.043 & $\mathbf{0 . 8 6 0}$ & $\mathbf{0 . 2 4 7}$ & $\mathbf{0 . 7 5 3}$ & $\mathbf{0 . 0 2 8}$ \\
Greece & $\mathbf{0 . 5 3 3}$ & $\mathbf{0 . 0 7 7}$ & $\mathbf{0 . 9 0 5}$ & $\mathbf{0 . 3 4 4}$ & $\mathbf{0 . 6 5 6}$ & $\mathbf{0 . 0 1 5}$ \\
Ireland & $\mathbf{0 . 4 6 8}$ & $\mathbf{- 0 . 0 2 6}$ & $\mathbf{0 . 9 4 4}$ & $\mathbf{0 . 3 1 1}$ & $\mathbf{0 . 6 8 9}$ & $\mathbf{- 0 . 0 0 9}$ \\
Italy & $\mathbf{0 . 6 4 9}$ & $\mathbf{0 . 1 0 8}$ & $\mathbf{0 . 7 9 8}$ & $\mathbf{0 . 3 8 0}$ & $\mathbf{0 . 6 2 0}$ & 0.012 \\
Netherlands & $\mathbf{0 . 5 6 8}$ & 0.017 & $\mathbf{0 . 9 1 3}$ & $\mathbf{0 . 3 4 4}$ & $\mathbf{0 . 6 5 6}$ & 0.002 \\
Portugal & $\mathbf{0 . 5 6 7}$ & $\mathbf{0 . 2 0 3}$ & $\mathbf{0 . 8 7 7}$ & $\mathbf{0 . 3 5 4}$ & $\mathbf{0 . 6 4 6}$ & $\mathbf{0 . 0 1 7}$ \\
Spain & $\mathbf{0 . 6 1 0}$ & 0.040 & $\mathbf{0 . 9 3 6}$ & $\mathbf{0 . 3 6 6}$ & $\mathbf{0 . 6 3 4}$ & 0.000 \\
Sweden & $\mathbf{0 . 4 6 0}$ & $\mathbf{0 . 2 2 1}$ & $\mathbf{0 . 8 6 4}$ & $\mathbf{0 . 2 9 6}$ & $\mathbf{0 . 7 0 4}$ & $\mathbf{0 . 0 2 6}$ \\
UK & $\mathbf{0 . 4 6 4}$ & 0.035 & $\mathbf{0 . 8 4 7}$ & $\mathbf{0 . 3 0 3}$ & $\mathbf{0 . 6 9 7}$ & $\mathbf{0 . 0 2 6}$ \\
USA & $\mathbf{0 . 3 1 2}$ & $\mathbf{0 . 2 0 1}$ & $\mathbf{0 . 8 2 7}$ & $\mathbf{0 . 2 0 4}$ & $\mathbf{0 . 7 9 6}$ & $\mathbf{0 . 0 4 9}$ \\
\hline \hline
\end{tabular}

Notes:This table shows the country-specific Weighted Mean Group (WMG)- Full Information Maximum Likelihood (FIML) panel estimates of the hybrid NKPC using disaggregate data. These are obtained by averaging the disaggregate FIML time-series estimation results across the $15(=\mathrm{N})$ sample sectors in a per-country basis (e.g. German agriculture, hunting and forestry, German construction, etc). The frequency of the variables in our dataset is annual and the sample period is 1971-2005 ( $\mathrm{T}=35$ ). The Gross Value Added (GVA) based weights used for WMG can be seen in Table B1 in Appendix B. They are calculated by dividing the average sectoral GVA by the average national GVA. Estimates in bold indicate statistical significance at the 5\% level. 
Table B5: Hybrid NKPC panel estimates, disaggregate data, country-specific MG-CCE

\begin{tabular}{lcccccc}
\hline \hline Country & $\delta$ & $\xi$ & $\rho$ & $\lambda^{b}$ & $\lambda^{f}$ & $\theta$ \\
\hline \hline Austria & 0.027 & -0.006 & $\mathbf{0 . 8 1 3}$ & -0.048 & $\mathbf{1 . 0 4 8}$ & 0.003 \\
Belgium & $\mathbf{0 . 1 4 7}$ & -0.055 & $\mathbf{0 . 7 7 8}$ & -0.007 & $\mathbf{1 . 0 0 7}$ & 0.064 \\
Denmark & 0.091 & $\mathbf{0 . 1 1 0}$ & $\mathbf{0 . 7 4 9}$ & 0.034 & $\mathbf{0 . 9 6 6}$ & 0.028 \\
France & $\mathbf{0 . 1 3 7}$ & $\mathbf{0 . 0 4 5}$ & 0.865 & 0.088 & $\mathbf{0 . 9 1 2}$ & 0.010 \\
Germany & $\mathbf{0 . 1 5 2}$ & $\mathbf{0 . 1 9 5}$ & $\mathbf{0 . 8 0 5}$ & $\mathbf{0 . 1 1 4}$ & $\mathbf{0 . 8 8 6}$ & 0.070 \\
Greece & $\mathbf{0 . 3 3 1}$ & -0.054 & $\mathbf{0 . 7 8 2}$ & $\mathbf{0 . 2 2 9}$ & $\mathbf{0 . 7 7 1}$ & 0.005 \\
Ireland & -0.015 & 0.073 & $\mathbf{0 . 7 9 5}$ & -0.027 & $\mathbf{1 . 0 2 7}$ & -0.017 \\
Italy & 0.034 & 0.013 & $\mathbf{0 . 7 8 1}$ & 0.003 & $\mathbf{0 . 9 9 7}$ & 0.000 \\
Netherlands & $\mathbf{0 . 3 8 2}$ & -0.103 & $\mathbf{0 . 8 4 4}$ & $\mathbf{0 . 2 4 3}$ & $\mathbf{0 . 7 5 7}$ & 0.007 \\
Portugal & $\mathbf{0 . 3 8 2}$ & -0.091 & $\mathbf{0 . 8 3 5}$ & $\mathbf{0 . 1 2 1}$ & $\mathbf{0 . 8 7 9}$ & -0.006 \\
Spain & $\mathbf{0 . 1 8 4}$ & -0.061 & $\mathbf{0 . 8 6 1}$ & $\mathbf{0 . 1 2 9}$ & $\mathbf{0 . 8 7 1}$ & -0.002 \\
Sweden & $\mathbf{0 . 1 5 2}$ & 0.005 & $\mathbf{0 . 7 7 2}$ & $\mathbf{0 . 1 1 3}$ & $\mathbf{0 . 8 8 7}$ & 0.000 \\
UK & $\mathbf{0 . 1 2 4}$ & 0.130 & $\mathbf{0 . 8 1 1}$ & $\mathbf{0 . 0 9 8}$ & $\mathbf{0 . 9 0 2}$ & $\mathbf{0 . 0 3 6}$ \\
USA & $\mathbf{0 . 1 2 9}$ & $\mathbf{0 . 2 1 3}$ & $\mathbf{0 . 7 4 0}$ & $\mathbf{0 . 0 8 9}$ & $\mathbf{0 . 9 1 1}$ & $\mathbf{0 . 0 7 5}$ \\
\hline \hline
\end{tabular}

Notes:This table shows the country-specific Mean Group (MG)- Constant Correlated Effect (CCE) panel estimates of the hybrid NKPC using disaggregate data. These are obtained by averaging the disaggregate CCE time-series estimation results across the $15(=\mathrm{N})$ sample sectors in a per-country basis (e.g. German agriculture, hunting and forestry, German construction, etc). The frequency of the variables in our dataset is annual and the sample period is 1971-2005 $(\mathrm{T}=35)$. Estimates in bold indicate statistical significance at the $5 \%$ level. 
Table B6: Hybrid NKPC panel estimates, disaggregate data, country-specific WMG-CCE

\begin{tabular}{lcccccc}
\hline \hline Country & $\delta$ & $\xi$ & $\rho$ & $\lambda^{b}$ & $\lambda^{f}$ & $\theta$ \\
\hline \hline Austria & 0.011 & 0.016 & $\mathbf{0 . 8 6 4}$ & -0.064 & $\mathbf{1 . 0 6 4}$ & $\mathbf{0 . 0 0 6}$ \\
Belgium & $\mathbf{0 . 0 6 4}$ & $\mathbf{0 . 0 9 7}$ & $\mathbf{0 . 9 0 1}$ & 0.040 & $\mathbf{0 . 9 6 0}$ & $\mathbf{0 . 0 3 7}$ \\
Denmark & $\mathbf{0 . 1 2 3}$ & $\mathbf{0 . 1 0 1}$ & $\mathbf{0 . 7 9 0}$ & $\mathbf{0 . 0 5 9}$ & $\mathbf{0 . 9 4 1}$ & $\mathbf{0 . 0 3 8}$ \\
France & $\mathbf{0 . 2 3 4}$ & $\mathbf{0 . 0 4 0}$ & $\mathbf{0 . 8 1 9}$ & $\mathbf{0 . 1 7 0}$ & $\mathbf{0 . 8 3 0}$ & 0.005 \\
Germany & 0.016 & $\mathbf{0 . 1 0 2}$ & $\mathbf{0 . 8 1 3}$ & -0.024 & $\mathbf{1 . 0 2 4}$ & $\mathbf{0 . 0 4 3}$ \\
Greece & $\mathbf{0 . 0 3 2}$ & $\mathbf{- 0 . 0 0 1}$ & $\mathbf{0 . 8 6 8}$ & $\mathbf{- 0 . 0 1 2}$ & $\mathbf{1 . 0 1 2}$ & $\mathbf{0 . 0 0 1}$ \\
Ireland & $\mathbf{- 0 . 1 4 1}$ & $\mathbf{- 0 . 0 6 2}$ & $\mathbf{0 . 8 4 3}$ & $\mathbf{- 0 . 2 2 6}$ & $\mathbf{1 . 2 2 6}$ & $\mathbf{- 0 . 0 2 9}$ \\
Italy & 0.031 & $\mathbf{0 . 2 7 0}$ & $\mathbf{0 . 6 6 6}$ & -0.001 & $\mathbf{1 . 0 0 1}$ & $\mathbf{0 . 1 6 5}$ \\
Netherlands & $\mathbf{0 . 2 9 7}$ & $\mathbf{- 0 . 0 9 8}$ & $\mathbf{0 . 8 3 6}$ & $\mathbf{0 . 1 9 4}$ & $\mathbf{0 . 8 0 6}$ & -0.005 \\
Portugal & $\mathbf{0 . 1 3 1}$ & 0.004 & $\mathbf{0 . 8 6 1}$ & $\mathbf{0 . 0 9 3}$ & $\mathbf{0 . 9 0 7}$ & 0.008 \\
Spain & $\mathbf{0 . 0 9 6}$ & 0.006 & $\mathbf{0 . 8 9 0}$ & $\mathbf{0 . 0 6 5}$ & $\mathbf{0 . 9 3 5}$ & 0.006 \\
Sweden & $\mathbf{0 . 0 7 1}$ & $\mathbf{0 . 1 1 1}$ & $\mathbf{0 . 8 5 3}$ & $\mathbf{0 . 1 5 6}$ & $\mathbf{0 . 8 4 4}$ & $\mathbf{0 . 0 3 9}$ \\
UK & $\mathbf{0 . 0 9 7}$ & $\mathbf{0 . 0 9 8}$ & $\mathbf{0 . 8 5 0}$ & $\mathbf{0 . 0 7 8}$ & $\mathbf{0 . 9 2 2}$ & $\mathbf{0 . 0 4 3}$ \\
USA & $\mathbf{0 . 1 3 4}$ & $\mathbf{0 . 2 9 8}$ & $\mathbf{0 . 7 8 4}$ & $\mathbf{0 . 0 9 4}$ & $\mathbf{0 . 9 0 6}$ & $\mathbf{0 . 1 0 9}$ \\
\hline
\end{tabular}

Notes:This table shows the country-specific Weighted Mean Group (WMG)-Constant Correlated Effect (CCE) panel estimates of the hybrid NKPC using disaggregate data. These are obtained by averaging the disaggregate CCE time-series estimation results across the $15(=\mathrm{N})$ sample sectors in a per-country basis. The CCE factors are estimated on a per country basis. The frequency of the variables in our dataset is annual and the sample period is 1971-2005 $(\mathrm{T}=35)$. Estimates in bold indicate statistical significance at the $5 \%$ level. 
Table B7: Hybrid NKPC panel estimates, disaggregate data, sector-specific WMG-CCE

\begin{tabular}{lcccccc}
\hline \hline Sector & $\delta$ & $\xi$ & $\rho$ & $\lambda^{b}$ & $\lambda^{f}$ & $\theta$ \\
\hline \hline Agriculture, Hunting and Forestry & $\mathbf{- 0 . 0 2 9}$ & $\mathbf{0 . 5 1 3}$ & $\mathbf{0 . 6 6 4}$ & $\mathbf{- 0 . 0 3 9}$ & $\mathbf{1 . 0 3 9}$ & $\mathbf{0 . 2 6 0}$ \\
Fishing & $\mathbf{0 . 1 8 3}$ & $\mathbf{0 . 2 0 6}$ & $\mathbf{0 . 8 1 3}$ & $\mathbf{0 . 1 1 9}$ & $\mathbf{0 . 8 8 1}$ & $\mathbf{0 . 1 2 5}$ \\
Mining and Quarrying & $\mathbf{0 . 2 4 4}$ & $\mathbf{0 . 9 5 4}$ & $\mathbf{0 . 6 2 8}$ & $\mathbf{0 . 1 8 9}$ & $\mathbf{0 . 8 1 1}$ & $\mathbf{0 . 3 6 8}$ \\
Total Manufacturing & $\mathbf{0 . 1 2 0}$ & 0.006 & $\mathbf{0 . 8 7 1}$ & $\mathbf{0 . 0 8 5}$ & $\mathbf{0 . 9 1 5}$ & 0.002 \\
Electricity, Gas and Water Supply & $\mathbf{0 . 2 2 6}$ & $\mathbf{0 . 0 8 4}$ & $\mathbf{0 . 8 7 0}$ & $\mathbf{0 . 1 7 3}$ & $\mathbf{0 . 8 2 7}$ & $\mathbf{0 . 0 5 2}$ \\
Construction & $\mathbf{0 . 3 5 9}$ & $\mathbf{0 . 0 4 6}$ & $\mathbf{0 . 7 4 4}$ & $\mathbf{0 . 2 4 8}$ & $\mathbf{0 . 7 5 2}$ & $\mathbf{0 . 0 2 6}$ \\
Whosale and Retail Trade & $\mathbf{- 0 . 0 9 5}$ & $\mathbf{0 . 2 0 5}$ & $\mathbf{0 . 6 4 7}$ & $\mathbf{- 0 . 1 2 1}$ & $\mathbf{1 . 1 2 1}$ & $\mathbf{0 . 1 1 8}$ \\
Hotels and Restaurants & $\mathbf{0 . 2 1 7}$ & $\mathbf{0 . 1 3 7}$ & $\mathbf{0 . 8 2 1}$ & $\mathbf{0 . 1 4 5}$ & $\mathbf{0 . 8 5 5}$ & $\mathbf{0 . 0 2 1}$ \\
Transport, Storage and Communication & $\mathbf{0 . 0 6 9}$ & $\mathbf{0 . 2 5 5}$ & $\mathbf{0 . 7 5 3}$ & $\mathbf{0 . 0 5 7}$ & $\mathbf{0 . 9 4 3}$ & $\mathbf{0 . 0 7 0}$ \\
Financial Intermediation & $\mathbf{0 . 0 9 0}$ & $\mathbf{0 . 4 7 9}$ & $\mathbf{0 . 7 1 5}$ & $\mathbf{0 . 0 7 7}$ & $\mathbf{0 . 9 2 3}$ & $\mathbf{0 . 1 6 2}$ \\
Real Estate, Renting and Business Act. & $\mathbf{0 . 0 9 0}$ & $\mathbf{0 . 0 4 2}$ & $\mathbf{0 . 9 2 0}$ & $\mathbf{0 . 0 6 6}$ & $\mathbf{0 . 9 3 4}$ & $\mathbf{0 . 0 1 1}$ \\
Public Admin., Def. and Comp. Soc. Sec. & $\mathbf{0 . 1 0 7}$ & $\mathbf{0 . 7 0 7}$ & $\mathbf{0 . 7 1 9}$ & $\mathbf{0 . 0 8 8}$ & $\mathbf{0 . 9 1 2}$ & $\mathbf{0 . 2 7 4}$ \\
Education & 0.032 & $\mathbf{0 . 2 3 1}$ & $\mathbf{0 . 7 1 7}$ & 0.015 & $\mathbf{0 . 9 8 5}$ & $\mathbf{0 . 1 2 7}$ \\
Health and Social Work & $\mathbf{0 . 3 6 9}$ & $\mathbf{0 . 0 8 8}$ & $\mathbf{0 . 8 9 3}$ & $\mathbf{0 . 2 3 9}$ & $\mathbf{0 . 7 6 1}$ & $\mathbf{0 . 0 0 4}$ \\
Other Community, Social and Pers. Serv. & $\mathbf{0 . 2 2 4}$ & $\mathbf{0 . 0 4 5}$ & $\mathbf{0 . 8 6 6}$ & $\mathbf{0 . 1 6 3}$ & $\mathbf{0 . 8 3 7}$ & $\mathbf{0 . 0 0 6}$ \\
\hline \hline
\end{tabular}

Notes:This table shows the sector-specific weighted Mean Group (WMG)- Constant Correlated Effect (CCE) panel estimates of the hybrid NKPC using disaggregate data. These are obtained by averaging the disaggregate CCE time-series estimation results across the $15(=\mathrm{N})$ sample sectors in a per-country basis. The CCE factors are estimated on a per country basis. The frequency of the variables in our dataset is annual and the sample period is 1971-2005 $(\mathrm{T}=35)$. The Gross Value Added (GVA) based weights used for WMG can be seen in Table B2-Panel A in Appendix B. They are calculated by dividing the average sectoral GVA of the given country by the sum of the average sectoral GVAs across the sample countries. The GVAs are expressed in common terms using 1997 German currency PPPs. Estimates in bold indicate statistical significance at the $5 \%$ level. 
Table B8: Hybrid NKPC panel estimates, disaggregate data, sector-specific WMG-FIML

\begin{tabular}{lcccccc}
\hline \hline Sector & $\delta$ & $\xi$ & $\rho$ & $\lambda^{b}$ & $\lambda^{f}$ & $\theta$ \\
\hline \hline Agriculture, Hunting and Forestry & $\mathbf{0 . 0 5 2}$ & $\mathbf{0 . 3 8 1}$ & $\mathbf{0 . 7 1 3}$ & 0.022 & $\mathbf{0 . 9 7 8}$ & $\mathbf{0 . 1 4 9}$ \\
Fishing & $\mathbf{0 . 3 0 1}$ & $\mathbf{0 . 0 4 5}$ & $\mathbf{0 . 8 2 9}$ & $\mathbf{0 . 1 9 2}$ & $\mathbf{0 . 8 0 8}$ & 0.002 \\
Mining and Quarrying & $\mathbf{0 . 3 0 5}$ & $\mathbf{0 . 1 1 4}$ & $\mathbf{0 . 8 4 2}$ & $\mathbf{0 . 2 3 2}$ & $\mathbf{0 . 7 6 8}$ & $\mathbf{0 . 0 1 4}$ \\
Total Manufacturing & $\mathbf{0 . 5 5 7}$ & $\mathbf{0 . 0 5 2}$ & $\mathbf{0 . 9 0 9}$ & $\mathbf{0 . 3 4 0}$ & $\mathbf{0 . 6 6 0}$ & -0.001 \\
Electricity, Gas and Water Supply & $\mathbf{0 . 3 4 3}$ & $\mathbf{0 . 1 4 4}$ & $\mathbf{0 . 9 1 2}$ & $\mathbf{0 . 2 4 9}$ & $\mathbf{0 . 7 5 1}$ & $\mathbf{0 . 0 0 9}$ \\
Construction & $\mathbf{0 . 5 8 7}$ & $\mathbf{- 0 . 1 2 1}$ & $\mathbf{0 . 8 1 6}$ & $\mathbf{0 . 3 6 4}$ & $\mathbf{0 . 6 3 6}$ & $\mathbf{- 0 . 0 1 2}$ \\
Whosale and Retail Trade & $\mathbf{0 . 4 5 4}$ & $\mathbf{0 . 2 3 3}$ & $\mathbf{0 . 6 9 5}$ & $\mathbf{0 . 3 0 3}$ & $\mathbf{0 . 6 9 7}$ & $\mathbf{0 . 0 5 8}$ \\
Hotels and Restaurants & $\mathbf{0 . 5 5 7}$ & $\mathbf{0 . 0 4 3}$ & $\mathbf{0 . 8 5 6}$ & $\mathbf{0 . 3 4 8}$ & $\mathbf{0 . 6 5 2}$ & $\mathbf{0 . 0 0 2}$ \\
Transport, Storage and Communication & $\mathbf{0 . 4 1 5}$ & $\mathbf{0 . 2 4 5}$ & $\mathbf{0 . 8 5 8}$ & $\mathbf{0 . 2 7 8}$ & $\mathbf{0 . 7 2 2}$ & $\mathbf{0 . 0 2 2}$ \\
Financial Intermediation & $\mathbf{0 . 2 0 9}$ & $\mathbf{0 . 4 7 7}$ & $\mathbf{0 . 7 3 1}$ & $\mathbf{0 . 1 6 0}$ & $\mathbf{0 . 8 4 0}$ & $\mathbf{0 . 1 4 2}$ \\
Real Estate, Renting and Business Act. & $\mathbf{0 . 2 4 6}$ & $\mathbf{- 0 . 0 2 0}$ & $\mathbf{0 . 9 3 4}$ & $\mathbf{0 . 1 5 0}$ & $\mathbf{0 . 8 5 0}$ & 0.001 \\
Public Admin., Def. and Comp. Soc. Sec. & $\mathbf{0 . 3 3 5}$ & $\mathbf{0 . 3 7 0}$ & $\mathbf{0 . 7 9 8}$ & $\mathbf{0 . 2 2 7}$ & $\mathbf{0 . 7 7 3}$ & $\mathbf{0 . 1 0 9}$ \\
Education & $\mathbf{0 . 2 1 7}$ & 0.018 & $\mathbf{0 . 7 8 0}$ & $\mathbf{0 . 1 1 7}$ & $\mathbf{0 . 8 8 3}$ & $\mathbf{0 . 0 3 3}$ \\
Health and Social Work & $\mathbf{0 . 6 3 2}$ & $\mathbf{0 . 1 0 0}$ & $\mathbf{0 . 9 3 4}$ & $\mathbf{0 . 3 8 2}$ & $\mathbf{0 . 6 1 8}$ & 0.000 \\
Other Community, Social and Pers. Serv. & $\mathbf{0 . 4 4 1}$ & $\mathbf{0 . 1 2 2}$ & $\mathbf{0 . 8 6 6}$ & $\mathbf{0 . 3 0 2}$ & $\mathbf{0 . 6 9 8}$ & $\mathbf{0 . 0 1 4}$ \\
\hline \hline
\end{tabular}

Notes:This table shows the sector-specific Weighted Mean Group (WMG)- Full Information Maximum Likelihood (FIML) panel estimates of the hybrid NKPC using disaggregate data. These are obtained by averaging the disaggregate FIML time-series estimation results across the $14(=\mathrm{N})$ sample countries in a per-sector basis (e.g. French construction, German construction, etc). The frequency of the variables in our dataset is annual and the sample period is 1971-2005 ( $\mathrm{T}=35)$. The Gross Value Added (GVA) based weights used for WMG can be seen in Table B2-Panel A in Appendix B. They are calculated by dividing the average sectoral GVA of the given country by the sum of the average sectoral GVAs across the sample countries. The GVAs are expressed in common terms using 1997 German currency PPPs. Estimates in bold indicate statistical significance at the $5 \%$ level.

Table B9: Hybrid NKPC panel estimates, disaggregate data, sector-specific MG-CCE

\begin{tabular}{lcccccc}
\hline \hline Sector & $\delta$ & $\xi$ & $\rho$ & $\lambda^{b}$ & $\lambda^{f}$ & $\theta$ \\
\hline \hline Agriculture, Hunting and Forestry & -0.009 & 0.103 & $\mathbf{0 . 7 7 7}$ & -0.034 & $\mathbf{1 . 0 3 4}$ & 0.049 \\
Fishing & 0.011 & -0.035 & $\mathbf{0 . 7 5 0}$ & -0.017 & $\mathbf{1 . 0 1 7}$ & -0.071 \\
Mining and Quarrying & $\mathbf{0 . 1 3 3}$ & $\mathbf{0 . 1 1 1}$ & $\mathbf{0 . 7 6 9}$ & $\mathbf{0 . 0 9 4}$ & $\mathbf{0 . 9 0 6}$ & $\mathbf{0 . 0 1 8}$ \\
Total Manufacturing & $\mathbf{0 . 0 9 2}$ & 0.030 & 0.827 & 0.037 & $\mathbf{0 . 9 6 3}$ & 0.016 \\
Electricity, Gas and Water Supply & 0.053 & 0.016 & $\mathbf{0 . 7 9 3}$ & 0.038 & $\mathbf{0 . 9 6 2}$ & 0.005 \\
Construction & $\mathbf{0 . 2 1 1}$ & -0.132 & $\mathbf{0 . 7 8 5}$ & 0.115 & $\mathbf{0 . 8 8 5}$ & -0.022 \\
Whosale and Retail Trade & $\mathbf{0 . 1 1 9}$ & -0.053 & $\mathbf{0 . 7 7 9}$ & 0.063 & $\mathbf{0 . 9 3 7}$ & -0.006 \\
Hotels and Restaurants & $\mathbf{0 . 1 2 3}$ & -0.033 & $\mathbf{0 . 8 0 7}$ & 0.082 & $\mathbf{0 . 9 1 8}$ & -0.015 \\
Transport, Storage and Communication & $\mathbf{0 . 1 3 0}$ & 0.087 & $\mathbf{0 . 8 2 0}$ & 0.069 & $\mathbf{0 . 9 3 1}$ & 0.027 \\
Financial Intermediation & 0.067 & $\mathbf{0 . 2 8 8}$ & $\mathbf{0 . 7 4 9}$ & 0.041 & $\mathbf{0 . 9 5 9}$ & 0.104 \\
Real Estate, Renting and Business Act. & $\mathbf{0 . 2 7 3}$ & $\mathbf{0 . 0 3 6}$ & $\mathbf{0 . 8 9 4}$ & $\mathbf{0 . 1 7 6}$ & $\mathbf{0 . 8 2 4}$ & 0.005 \\
Public Admin., Def. and Comp. Soc. Sec. & $\mathbf{0 . 2 4 6}$ & -0.016 & $\mathbf{0 . 8 3 3}$ & $\mathbf{0 . 1 6 6}$ & $\mathbf{0 . 8 3 4}$ & 0.023 \\
Education & $\mathbf{0 . 2 6 4}$ & -0.143 & $\mathbf{0 . 8 3 6}$ & $\mathbf{0 . 1 8 4}$ & $\mathbf{0 . 8 1 6}$ & -0.011 \\
Health and Social Work & $\mathbf{0 . 2 9 1}$ & 0.116 & $\mathbf{0 . 8 0 7}$ & $\mathbf{0 . 1 9 8}$ & $\mathbf{0 . 8 0 2}$ & 0.012 \\
Other Community, Social and Pers. Serv. & $\mathbf{0 . 2 2 2}$ & 0.059 & $\mathbf{0 . 8 5 3}$ & $\mathbf{0 . 1 5 0}$ & $\mathbf{0 . 8 5 0}$ & 0.012 \\
\hline \hline
\end{tabular}

Notes:This table shows the sector-specific Mean Group (MG)- Constant Correlated Effect (CCE) panel estimates of the hybrid NKPC using disaggregate data. These are obtained by averaging the disaggregate CCE time-series estimation results across the $14(=\mathrm{N})$ sample countries in a per-sector basis (e.g. French construction, German construction, etc). The frequency of the variables in our dataset is annual and the sample period is 1971-2005 ( $\mathrm{T}=35)$. Estimates in bold indicate statistical significance at the $5 \%$ level. 


\section{Appendix C}

Figure 1: Hybrid NKPC time-series estimates of $\delta$, disaggregate data, FIML
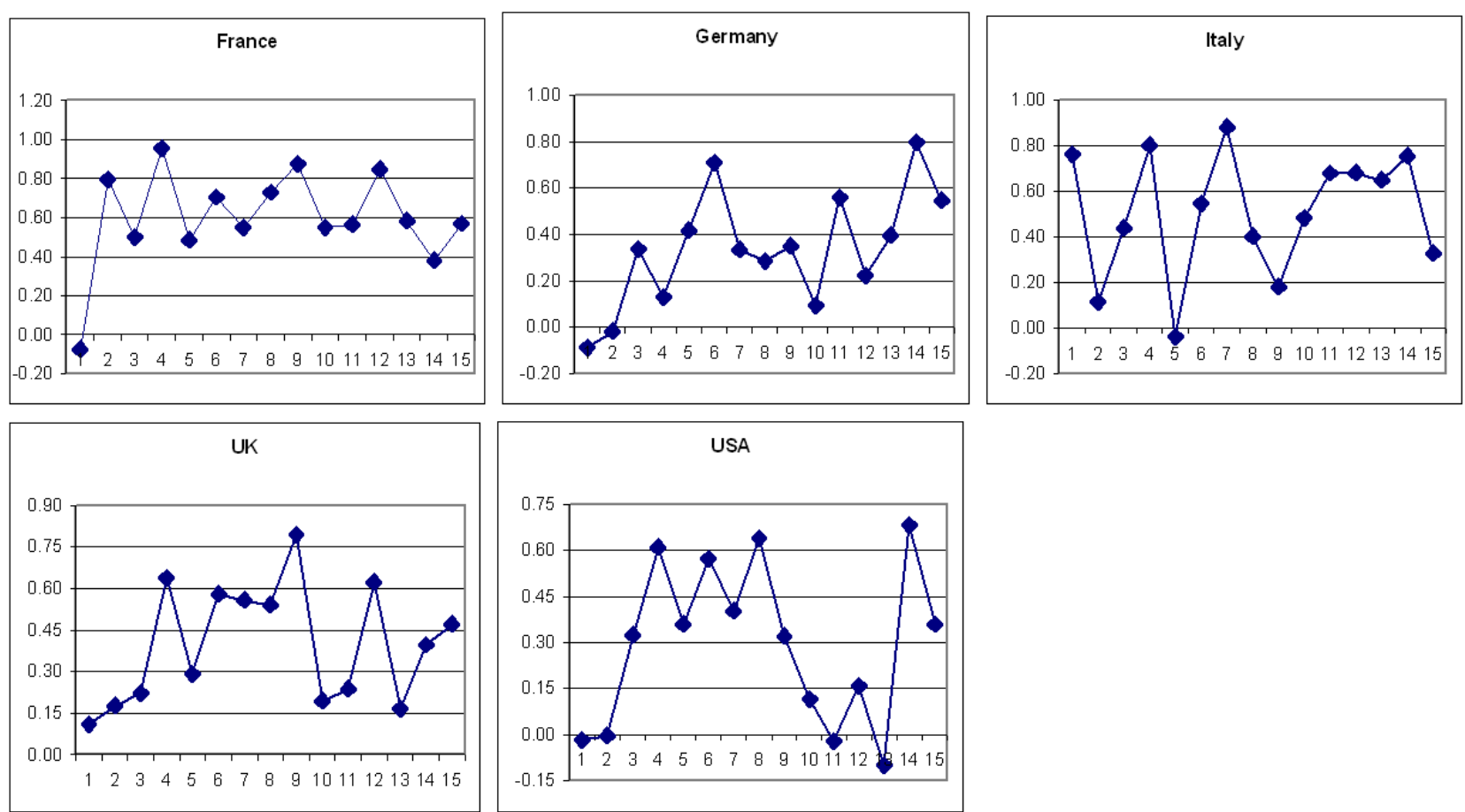

Notes: This figure shows the disaggregate data Full Information Maximum Likelihood (FIML) time-series point estimates of $\delta$. The frequency of the variables in our dataset is annual and the sample period is 1971-2005 $(\mathrm{T}=35)$. The horizontal axis units correspond to the 15 sample sectors. Particularly, 1: agriculture, hunting and forestry; 2: fishing; 3: mining and quarrying; 4: total manufacturing; 5: electricity, gas and water supply; 6: construction; 7: wholesale and retail trade; 8: hotels and restaurants; 9: transport, storage and communication; 10: financial intermediation; 11: real estate, renting and business activities; 12: public administration, defence and compulsory social security; 13: education; 14: health and social work; 15: other community, social and personal services. 
Figure 2: Hybrid NKPC time-series estimates of $\xi$, disaggregate data, FIML
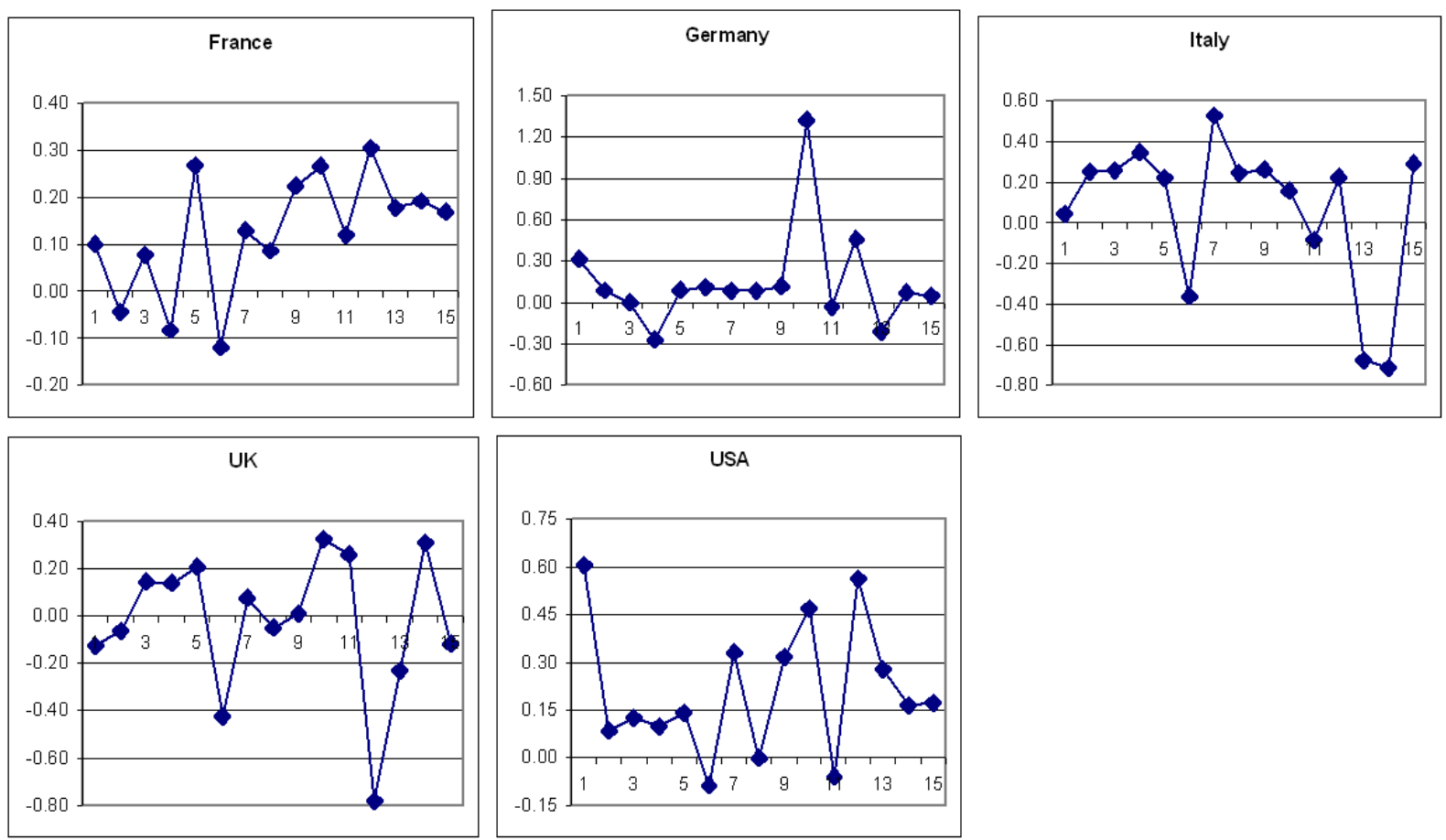

Notes: This figure shows the disaggregate data Full Information Maximum Likelihood (FIML) time-series point estimates of $\xi$. See also the notes of Figure 1. 
Figure 3: Hybrid NKPC time-series estimates of $\rho$, disaggregate data, FIML
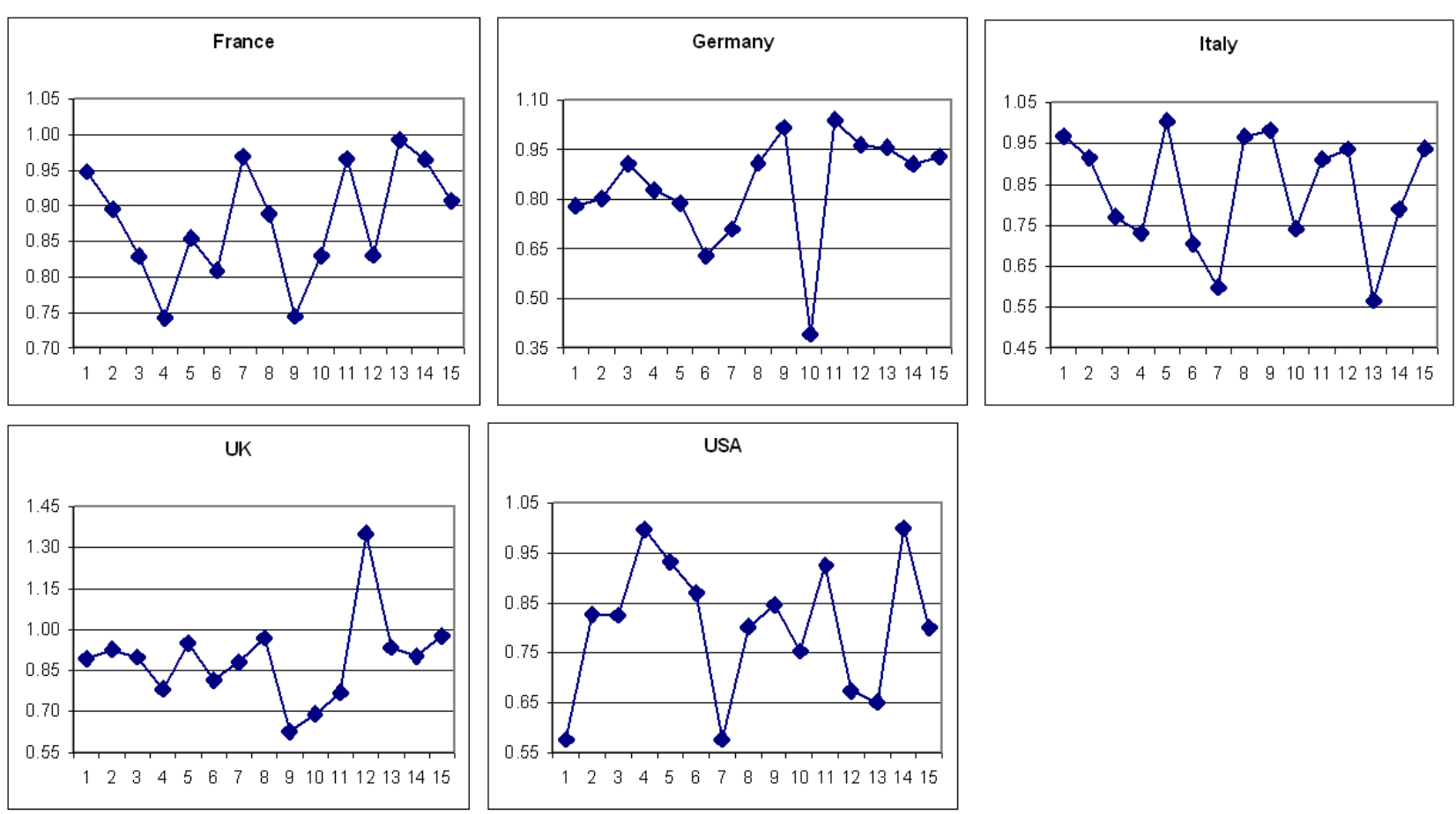

Notes: This figure shows the disaggregate data Full Information Maximum Likelihood (FIML) time-series point estimates of $\rho$. See also the notes of Figure 1. 